\title{
Conceptual design of a Ni-based chemical looping combustion process using fixed- beds
}

J.R. Fernández*, J.C. Abanades

Instituto Nacional del Carbón, CSIC-INCAR Spanish Research Council, Oviedo, Spain

*Corresponding author: Jose Ramon Fernandez, jramon@incar.csic.es, CSIC-INCAR

Spanish Research Council, Francisco Pintado Fe, 26, 33080, Oviedo, Spain

Telephone:+34 985119090, Fax:+34 985297662

\section{Abstract}

This work presents a comprehensive conceptual design of a Ni-based chemical looping combustion process (CLC) carried out in fixed bed reactors. The process is intended to exploit the well-known advantages of the $\mathrm{Ni} / \mathrm{NiO}$ redox system for CLC applications in terms of high reactivity, $\mathrm{O}_{2}$ carrying capacity and chemical and thermal stability. Solutions to the problem of heat management in fixed bed reactors at high temperature and high pressure are described, while a continuous flow of nitrogen for driving a gas turbine is produced. Each reactor involved in the process goes through a cyclic sequence of five reaction and heat transfer stages. Cool product gas recirculations are incorporated into the $\mathrm{Ni}$ oxidation and $\mathrm{NiO}$ reduction stages in order to moderate the maximum temperatures in the beds and control the displacement of the reaction and heat transfer fronts. A preliminary conceptual design of the process has been carried out to determine the minimum number of reactors needed for continuous operation in typical large-scale $\mathrm{CO}_{2}$ capture systems. Basic reactor models and assumptions based on an ideal plug flow pattern have been used in all the reactors during the chemical reactions and the heat transfer operations. This has made it possible to identify reasonable operating windows for the eight fixed-bed reactors that make up the $\mathrm{CO}_{2}$ 
capture system, and has demonstrated not only its technical viability but also its great potential for further development.

Keywords: chemical looping combustion, Ni-based oxygen carrier, adiabatic fixed-bed reactor, $\mathrm{CO}_{2}$ capture, gas recycle.

\section{Introduction}

The concentration of carbon dioxide in the atmosphere has strongly increased over the last few decades as a result of the dependency on fossil fuels for energy production. $\mathrm{CO}_{2}$ represent the largest contribution to the global anthropogenic greenhouse gas emissions. It is generally accepted that a drastic reduction in $\mathrm{CO}_{2}$ emissions is necessary in a short period of time and among the various strategies proposed, Carbon Capture and Storage (CCS) is considered as a valid mid-term solution. The $\mathrm{CO}_{2}$ capture step is nowadays the most energy intensive step in CCS. For that reason, there is a great interest worldwide in developing new $\mathrm{CO}_{2}$ capture technologies aimed at reducing the energy penalty and the cost of existing equipment [1].

Chemical looping combustion (CLC) is an emerging technology for the clean combustion of natural gas and other fuels with inherent $\mathrm{CO}_{2}$ capture, which consists in the transfer of oxygen from air to the fuel by means of a solid oxygen carrier (typically a metal), avoiding any direct contact between the fuel and air [2-9]. Chemical looping combustion has been mainly proposed to be accomplished in a configuration consisting of interconnected fluidized-bed reactors [4, 10-14]. This configuration facilitates the transport of the oxidized carrier to the fuel reactor and its subsequent regeneration in the air reactor. The small size of the particles ensures there is a good contact between the gas and solids, which accelerates the kinetics of the reactions involved. Moreover, the rapid mixing of the solids in fluidized beds favours the control of the temperature in the 
characteristic energy-intense reactions of CLC processes. Fluidized bed CLC concepts have been demonstrated in several experimental pilot units in recent years [15-20].

However, when the reference system without capture is a high efficiency natural gas combined cycle (NGCC), only the operation of CLC processes at high temperatures and pressures makes it possible to achieve high overall efficiencies in CLC systems [21]. Theoretical studies have highlighted the advantages in terms of energy efficiency of CLC systems performed in interconnected fluidized beds (CFB) at high pressure upstream of the gas turbine [22]. Nevertheless, this high pressure fluidized bed concept is still in a very early stage of development [23-25] and needs to be experimentally validated in order to demonstrate its feasibility on a large scale. Moreover, a high temperature and high pressure solids filtering system is required to remove the fines that result from the unavoidable particle attrition in fluidized-bed systems. The presence of particles in the outlet stream can negatively affect the performance of the downstream gas turbine. In addition, considerable concern has recently been expressed concerning the potential risks for human health and the environment posed by the emissions of trace compounds of some oxygen carriers, such as $\mathrm{Ni}$ or $\mathrm{Co}$ [9]. This is particularly unfortunate in the case of Ni-based materials, because they have been extensively studied and have shown some of the best performances as oxygen carriers for chemical looping combustion from lab scale test to pilot plants up to $120 \mathrm{~kW}_{\text {th }}[10,26-28]$ and chemical looping reforming [29, 30]. They exhibit a very high reactivity and reversibility at temperatures up to $1200{ }^{\circ} \mathrm{C}$ - $1300{ }^{\circ} \mathrm{C}$, a very high oxygen carrying capacity and few thermodynamic restrictions for the complete methane conversion to $\mathrm{CO}_{2}$ and $\mathrm{H}_{2} \mathrm{O}$. Ni based materials require an inert support because unsupported $\mathrm{NiO}$ particles have shown low reaction rates and a strong tendency to agglomeration [31]. Among available support materials, alumina $\left(\mathrm{Al}_{2} \mathrm{O}_{3}\right)$, nickel aluminate $\left(\mathrm{NiAl}_{2} \mathrm{O}_{4}\right)$ and 
magnesium aluminate $\left(\mathrm{MgAl}_{2} \mathrm{O}_{4}\right)$ have received the widest attention due to their mechanical strength and thermal stability [28, 32-34]. These kind of Ni-based materials are also commonly used in large scale applications such as conventional steam reforming [35] and secondary reforming for producing ammonia or methanol [36] due to their excellent catalytic performance and thermal stability in fixed-bed reactors under harsh operating conditions of high temperature $\left(1000{ }^{\circ} \mathrm{C}\right)$ and high pressure $(35$ bar), with no material losses to the gas phase.

Few chemical looping combustion processes have been proposed in configurations based on packed bed reactor technology [37-39]. In these reactors, the oxygen carrier is stationary and it is alternately exposed to reducing and oxidizing atmospheres by means of the periodic switching of the gas feeds (fuel gas and air, respectively). At least two reactors working alternately in parallel ensure the production of a continuous high temperature and high pressure gas stream [38], that is able to efficiently drive a gas turbine for power generation in combination with a steam cycle, and also a concentrated stream of $\mathrm{CO}_{2}$ suitable for transport and storage (see Fig. 1). In contrast to FB configurations, where even minor attrition rates may be unacceptable for hazardous $\mathrm{Ni}$ compounds, operational problems derived from attrition in the oxygen carrier are expected to be negligible when operating with pellets in fixed beds. Cyclones and filters for gas-solid separation are not required, which allows more compact reactor designs. In contrast, more complex heat management strategies and the need of switching valves operating with gases at very high temperature are required in packed-bed systems. Some manufacturers already offer high-temperature valves made of materials that can withstand operating temperatures higher than $1000^{\circ} \mathrm{C}$ [40], and valves with inner watercooled components that are commonly used in a large number of high temperature industrial applications. Therefore, the development of valves suitable for the scaling up 
of CLC applications should not be an obstacle for these kinds of process schemes until a detailed economic analysis of specific process schemes can be carried out.

Wide industrial experience is available in the control and operation of pressure and temperature swing adsorption systems that could be implemented to fixed bed CLC configurations, such as that represented in Fig. 1. However, very few publications are available on CLC in fixed-beds full process systems. General Electric investigated a fixed bed chemical looping reforming concept, called "unmixed reforming", in which the exothermic oxidation of a metal $(\mathrm{Ni}, \mathrm{Cu}, \mathrm{Fe})$ supplies the heat required for the endothermic calcination of a Ca-based sorbent (previously carbonated in a reforming stage), that takes place in the same matrix bed $[37,41]$. These early works experimentally demonstrated that the redox reactions involved in CLC process can proceed very rapidly, evolving through the fixed bed in narrow reaction fronts, in a highly effective cyclic operation involving several dynamically operated fixed- bed reactors. A few recent studies have attempted to demonstrate theoretically and experimentally the feasibility of other CLC concepts in fixed-bed configurations for $\mathrm{CO}_{2}$ capture at large scale $[38,42-48]$. The key to understand their advantages and limitations is the strategy adopted to control the increase in temperature in the solids bed as the reaction front advances through the reactor, especially during the exothermic metal oxidation stage. Since most of the oxygen carriers proposed in the literature lose their reactivity and tend to agglomerate at temperatures higher than $1100-1200{ }^{\circ} \mathrm{C}$ [9], careful control of the temperature in the reaction fronts is required when highly exothermic reactions take place. The mass and heat balances around a moving reaction front indicate that the increase in temperature in the reaction fronts is determined by the composition, the thermal properties and the temperature of the inlet gas, in addition to the initial temperature, the thermal properties and the inert content of the solids bed [ 38 , 
45]. During CLC operation, both the reaction and solid/gas heat exchange fronts move along the fixed-beds at different velocities, depending mainly on the concentration and molecular weights of the reactants and on the stoichiometry of the reactions. In the studies reported by Noorman and co-workers [38, 43, 49-51] air is directly fed into the air reactor to carry out the oxidation stage. In this situation, the reaction front normally moves forward faster than the gas/solid heat exchange front, that is gradually left behind. Consequently, the gas arrives at the reaction front having already been preheated by the previously oxidized solids, which in turn have been heated by the heat released in the oxidation reaction. The presence of a large amount of inert material in bed composition makes it possible to separate the advance of the reaction and heat exchange fronts. There will be therefore a larger mass of solids between them, which will be serve to absorb the heat from the exothermic reaction. This will result in a lower increase in temperature in the reaction front during the oxidation stage. For this reason, for oxygen carriers with a high carrying capacity and a high oxidation enthalpy, such as $\mathrm{Ni}$ or $\mathrm{Cu}$, a maximum metal loading of $15-20 \mathrm{wt} . \%$ is recommended by Noorman et al [38] in order to avoid undesirable hot spots. This is a handicap for the economic viability of the process, because with a large fraction of inert solids in the bed, larger high-pressure reactors will be required to convert the same amount of natural gas fed into the system. Such system will obviously require higher level of investment in high pressure reactors and more rigorous safety requirements.

Alternative fixed bed configurations based on syngas as fuel have recently been proposed $[46,52]$ to ensure suitable heat management in the specific case of a system of packed bed reactors for CLC. In these cases, the use of a high inert content (higher than $67 \mathrm{wt.} \%$ ) and the low reduction enthalpy of the syngas allows the temperature profiles to be moderated during the CLC operation. An alternative to this strategy for heat 
management was proposed in an previous work by Fernández et al. [45] devoted to a novel $\mathrm{Ca} / \mathrm{Cu}$ chemical looping process for hydrogen production and/or power generation. The control of the temperature in the reaction front during the necessary $\mathrm{Cu}$ oxidation stage was carried out by recycling a large amount of the cooled product gas (mainly composed of nitrogen) in order to dilute the $\mathrm{O}_{2}$ fed into the reactor. In these conditions, the operation can be carried out with higher $\mathrm{Cu}$ content in the solid bed $(>30$ $w t \%)$ without exceeding the maximum allowable temperature in the reaction front, thereby allowing a more compact reactor design, at the expense of the energy and equipment cost linked to such recycle of cold gas.

This work proposes a similar strategy for controlling the temperature in Ni-based chemical looping combustion (CLC) applications using methane as fuel with the aim of exploiting the inherent advantages of the $\mathrm{Ni} / \mathrm{NiO}$ redox system. The objective of this study is to demonstrate the theoretical viability of this novel Ni-based CLC system by incorporating state-of-the-art knowledge of the thermodynamics and kinetics of the main gas/solid reactions involved, and to develop a comprehensive conceptual design in which the operational strategy and conditions are fully defined for each step of the process.

\section{Basic reactor design and operating conditions}

The process proposed in this work is conceptually based on the chemical looping combustion of methane for power generation by means of a $\mathrm{Ni} / \mathrm{NiO}$ chemical loop, but it can be extended to other fuels and oxygen carriers. The fixed bed configuration shown in Fig. 1 requires a system of adiabatic packed bed reactors dynamically operated at high pressure and high temperature. It is obvious that such a system cannot operate with only two alternate steps, because the final state of the reactor at the end of one reaction stage (in terms of solids temperature and conversion profiles) does not 
necessarily meet the conditions for initiating the next reaction stage (the solids would be too cold and/or already converted). Additional stages are therefore needed to ensure that the final reactor conditions after each stage are those needed for the beginning of the next stage.

The performance of the reactors in each stage of the process can be approximately represented using a basic reactor model, where the reaction rates are assumed to be sufficiently fast to take place in narrow reactions fronts that advance along the packed bed as the reacting gases are fed in and the oxygen carrier is converted. This assumption was adopted by Noorman et al. [38] and Fernandez et al. [45] to theoretically describe the cyclic operation of fixed-bed reactor systems for chemical looping combustion applications and for the $\mathrm{Ca} / \mathrm{Cu}$ looping process, respectively. Recent studies have provided experimental evidence that this assumption is correct in fixed-bed reactors for CLC processes $[49,51]$.

Therefore, an ideal plug flow model can be considered as a reasonable representation of the flow pattern in large scale packed beds, in which the solid-gas reactions proceed rapidly and axial gas dispersion effects can be neglected. It is assumed that the density of the solids and the heat capacity of solid and gas are constant. Moreover, the pressure drop along the bed and the variation of the mass flow rate by the gas/solid reaction are considered negligible. The energy balance, assuming that the heat (released or consumed if the reaction is exothermic or endothermic, respectively) is taken by/from the solids when the gas reacts with them, can be expressed as follows [38]:

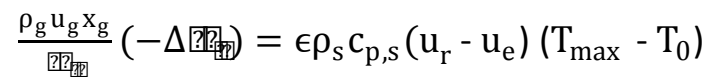

Under these conditions, the velocity of the reaction fronts along the fixed beds $\left(u_{r}\right)$ can be calculated by means of a mass balance in the reaction front as follows [38]: 


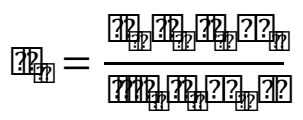

where $\rho_{\mathrm{g}}$ and $\rho_{\mathrm{s}}$ represent the density of the gas and the solid, respectively, $\mathrm{u}_{\mathrm{g}}$ is the superficial gas velocity, $x_{i}$ denotes the mass fraction of the gas/solid component, $M_{i}$ is the molecular weight, $\varepsilon$ is the porosity, and $\varphi$ is the stoichiometric factor of the gas/solid reaction.

Moreover, when the reactions involved are not thermally neutral and/or when the temperatures of the gases and the solids in contact are different, heat exchange fronts are also established. The velocity at which the heat fronts move towards the exit of the reactor $\left(\mathrm{u}_{\mathrm{e}}\right)$ can be estimated by means of a heat balance in these heat exchange fronts, as follows [38]:

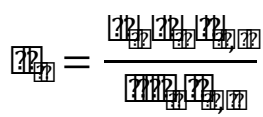

An intense heat transfer between gases and solids can also be assumed in the model, when the operation is carried out at high superficial velocities and pressures. Therefore, the temperature of the gases and the solids is assumed to be very similar along the bed, which makes it possible to explain each cyclic operation using a single axial temperature profile along the entire reactor.

During the first stage of the process, a stream of methane is oxidized to $\mathrm{CO}_{2}$ and $\mathrm{H}_{2} \mathrm{O}$ by the NiO-based oxygen carrier contained in the packed bed, which is reduced to Ni. For this study, it is assumed that the packed bed initially contains a totally oxidized oxygen carrier ( $\mathrm{NiO}$ over an inert support) and that a significant part of the bed is at high temperature $\left(\mathrm{T}_{\mathrm{s} 1}\right.$ in Fig. 2), as a result of the oxidation stage of the previous cycle, as will be described later. $\mathrm{T}_{\mathrm{s} 1}$ must be sufficiently high to allow very fast reduction kinetics from the very beginning of the operation. The fuel gas, which is fed into the 
fixed-bed at high pressure and moderate temperature $\left(\mathrm{T}_{\text {gin, },}\right)$, is introduced into the part of the reactor where the solids are at the highest temperature $\left(\mathrm{T}_{\mathrm{s} 1}\right)$. The reduction front will move forward in a narrow reaction front (indicated in Fig. 2 as the transition between the white and grey zones, r). Since the reduction of $\mathrm{NiO}$ to $\mathrm{Ni}$ with methane is highly endothermic, a sufficient quantity of sensible heat must be contained in the fraction of the bed at $T_{\mathrm{s} 1}$ in order to sustain the advance of the reaction front until it exits the reactor. As the bed is initially divided into two zones of different temperatures $\left(T_{\mathrm{s} 1}\right.$ and $\left.T_{\mathrm{s} 2}\right)$ and the fuel gas is also fed into the reactor at another temperature $\left(\mathrm{T}_{\text {gin,r }}\right)$, two heat exchange fronts, $e_{1}$ and $e_{2}$ (represented in Fig. 2 as the transitions $T_{\text {gin, } \mathrm{r}} / \mathrm{T}_{1}$ and $T_{\mathrm{s} 1} / T_{\mathrm{s} 2}$, respectively) are formed, and they move forward at velocities $\left(\mathrm{u}_{\mathrm{e} 1}\right.$ and $\left.\mathrm{u}_{\mathrm{e} 2}\right)$ that can be calculated from Eq. (3). As will be illustrated later in a case study, the typical conditions for carrying out this reduction stage make the reaction front move faster than the heat exchange fronts $\left(\mathrm{u}_{\mathrm{r}}>\mathrm{u}_{\mathrm{e}}\right)$ and as a result, a heat plateau appears in the bed $\left(\mathrm{T}_{1}\right)$, as shown in Fig. $2\left(t=t_{1}\right)$. Under these circumstances, the gas will arrive at the reaction front having been already preheated by the reduced solids, which in turn will have been cooled down from $T_{s 1}$ to $T_{1}$ due to the consumption of heat by the endothermic reduction of $\mathrm{NiO}$ to $\mathrm{Ni}$ by methane. The maximum decrease in temperature in the reaction front $\left(\Delta \mathrm{T}_{\max }\right.$ in Fig. 2) can be calculated by means of an energy balance at the reaction front (Eq. 4) and it mainly depends on the enthalpy of reduction, the stoichiometry of the reaction and the concentration of the gas/solid reagents [38].

$$
\Delta \mathrm{T}_{\max }=\frac{-\Delta \mathrm{H}_{\mathrm{r}}}{\frac{\mathrm{c}_{\mathrm{ps}} \mathrm{M}_{\mathrm{NiO}}}{\mathrm{x}_{\mathrm{NiO}} \varphi}-\frac{\mathrm{c}_{\mathrm{pg}} \mathrm{M}_{\mathrm{CH} 4}}{\mathrm{x}_{\mathrm{CH} 4}}}
$$

Because of the favorable conditions for the heat transfer between the gas and the solids, the product gas (composed mainly of $\mathrm{CO}_{2}$ and $\mathrm{H}_{2} \mathrm{O}$ ) is discharged from the beginning at 
a constant temperature that corresponds to the initial temperature of the solids located closest to the exit of the reactor $\left(\mathrm{T}_{\mathrm{s} 2}\right)$. This occurs until the heat exchange front $\left(\mathrm{e}_{2}\right)$, marked as the transition $\mathrm{T}_{\mathrm{s} 1} / \mathrm{T}_{\mathrm{s} 2}$, reaches the exit. During the rest of the operation, the flue gas abandons the bed at $\mathrm{T}_{\mathrm{s} 1}$. When the bed achieves its total conversion (Fig. 2, $\mathrm{t}=\mathrm{t}_{\text {end }}$ ), the part of the solids that has been crossed by all the fronts is left at the temperature of the incoming gas $\left(\mathrm{T}_{\text {gin, } \mathrm{r}}\right)$, while the rest of the solids, which have not been reached by the heat exchange front $\left(\mathrm{e}_{1}\right)$, marked as the transition $\left.\mathrm{T}_{\text {gin, } \mathrm{r}} / \mathrm{T}_{1}\right)$, will remain at $T_{1}$.

Part of the product gas can be recirculated and reintroduced into the system in order to improve the heat management during the reduction stage. This should also prevent carbon deposition by thermal cracking or $\mathrm{CH}_{4}$ decomposition due to the presence of recycled steam and $\mathrm{CO}_{2}$ in the feed [53]. This gas recirculation can also be designed to increase the velocity of the heat exchange fronts through the bed and make both reaction front (r) and heat exchange front $\left(\mathrm{e}_{2}\right)$ reach the reactor exit at the same time. The decreasing separation between both fronts ( $\mathrm{r}$ and $\mathrm{e}_{2}$ in Fig. 2) will allow the reduction stage to be initiated with a low fraction of solids at high temperature $\left(\mathrm{T}_{\mathrm{s} 1}\right)$. This is important because a higher proportion of the heat generated in the subsequent oxidation stages (explained below) can be used to produce $\mathrm{N}_{2}$ at a high enough temperature and a high enough pressure to be expanded in a gas turbine for power generation.

A reasonable recirculation ratio must be established for each particular case in order to avoid an excessive drop in temperature in the reduction front. The temperature of the plateau formed behind the reduction front $\left(T_{1}\right)$ must be sufficiently high to allow from the very beginning the rapid oxidation of the Ni-based carrier in the subsequent stage of the CLC process. As pointed out above, once the oxygen carrier has been completely reduced, a new reaction stage is initiated, which begins with the temperature profile left 
at the end of the reduction stage (Fig. $2, \mathrm{t}=\mathrm{t}_{\text {end }}$ ). The oxidation stage is assumed to take place under operating conditions that will allow total solid and oxygen conversion inside the reactor. Consequently, the gas discharged will be mainly composed of nitrogen. The oxidation of $\mathrm{Ni}$ to $\mathrm{NiO}$ is highly exothermic and, under certain conditions, the temperature may escalate out of control in the reaction front, leading to the irreversible loss of solids activity due to sintering or agglomeration. In order to regulate the maximum temperature during the oxidation stage, it is necessary to keep the advance of the reaction front and heat exchange front sufficiently apart so that there will be more solids between them and therefore a more moderate increase in temperature.

There are two possible strategies for carrying out the $\mathrm{Ni}$ oxidation stage to avoid reaching maximum temperatures in the reaction front that could lead to irreversible loss of the solid activity due to sintering or agglomeration. The first possibility is to use an oxygen carrier with a low active phase content ( $<20$ wt.\%) [38], which will allow a high concentration of $\mathrm{O}_{2}(21 \mathrm{vol} . \%)$ to be fed into the air reactor. This option will make the reaction front advance much faster than the heat exchange front $\left(u_{r} / u_{e}>1\right)$. The second approach [45] is to use an oxygen carrier with the highest allowable content of active phase (>50 wt.\%), which will make necessary a large dilution of the $\mathrm{O}_{2}$ in the feed. The reaction front will then move through the bed much more slowly than the heat exchange front $\left(\mathrm{u}_{\mathrm{r}} / \mathrm{u}_{\mathrm{e}}<1\right)$.

For this work, we have chosen the second option because the increase in the inert content in the fixed-bed reactors involves larger reactor volumes to convert the same amount of gas fed into the system. Larger reactors operating at high pressure require more costly equipment, thicker reactor walls and additional security arrangements. Moreover, the excess of inert can act as thermal ballast that could make it necessary to include additional heat exchange steps (or steps of longer duration) between the reaction 
stages in order to accommodate the temperature of the solids and gases present in the process.

As shown in Fig. 3, the mixture of air and recycled nitrogen is fed in through the part of the reactor where the solids are at higher temperature $\left(T_{1}\right)$, once the reduction stage has been completed. From the very beginning, this temperature must be sufficiently high to allow fast oxidation rates and the complete conversion of $\mathrm{O}_{2}$ in a very narrow reaction front, even with a low content of $\mathrm{O}_{2}$ present in the feed. Since the heat exchange front $\left(e_{1}\right)$ moves ahead of the reaction front $(r)$, the gas arrives at the reaction front at the inlet gas temperature $\left(\mathrm{T}_{\text {gin,o }}\right)$ and heats up due to the exothermicity of the oxidation reaction $\left(\Delta \mathrm{H}_{298 \mathrm{~K}}=-239 \mathrm{~kJ} / \mathrm{mol} \mathrm{Ni}\right)$. As the heat of reaction is released in the reaction front, it is transported forward by the nitrogen leaving the reaction front and, as a result, the solids downstream (initially at $\mathrm{T}_{1}$ ) gradually increase their temperature. Meanwhile, the part of the bed that has already been oxidized is left behind at the inlet gas temperature $\left(\mathrm{T}_{\text {gin,o }}\right)$. In this case, the maximum adiabatic increase in temperature in the reaction front $\left(\Delta \mathrm{T}_{\max }\right.$ in Fig. 3) can be calculated from Eq. (5):

$$
\Delta \mathrm{T}_{\mathrm{max}}=\frac{-\Delta \mathrm{H}_{\mathrm{Qxx}}}{\frac{\mathrm{C}_{\mathrm{gr}} \mathrm{M}_{\mathrm{O} 2}}{\mathrm{x}_{\mathrm{O} 2}}-\frac{\mathrm{C}_{\mathrm{gg}} \mathrm{M}_{\mathrm{N1}}}{\mathrm{x}_{\mathrm{N} 1} \varphi}}
$$

Since the gas arrives at the reaction front at the inlet temperature $\left(\mathrm{T}_{\mathrm{gin}, \mathrm{o}}\right)$, the maximum temperature achieved in the reaction front $\left(\mathrm{T}_{\max }\right)$ under adiabatic conditions can be estimated as follows:

$\mathrm{T}_{\max }=\mathrm{T}_{\text {gin,o }}+\Delta \mathrm{T}_{\max }$

Under these circumstances, the inlet gas temperature needs to be low in order to moderate $\mathrm{T}_{\max }$, as indicated in Eq. (6), so that this parameter does not exceed the maximum temperature permitted during the operation. Once the solids have reached the 
maximum temperature, the heat released by the oxidation reaction will be absorbed by the expanding fraction of solids in the bed at $\mathrm{T}_{\max }$ as the heat transfer front $\left(\mathrm{e}_{1}\right)$ moves forward (see Fig. 3, $\mathrm{t}=\mathrm{t}_{1}$ ).

As in the reduction stage, the bed is initially divided into two zones with different temperatures $\left(T_{1}\right.$ and $\left.T_{\text {gin,r }}\right)$ and the feed is also introduced at another temperature $\left(\mathrm{T}_{\text {gin,o }}\right)$. Therefore, two heat exchange fronts, $\mathrm{e}_{1}$ and $\mathrm{e}_{2}$ (represented in Fig. 3 as the transitions $T_{\max } / T_{1}$ and $T_{1} / T_{\text {gin,r, }}$, respectively) are formed, and they move forward towards the reactor exit at two velocities $\left(\mathrm{u}_{\mathrm{e} 1}\right.$ and $\left.\mathrm{u}_{\mathrm{e} 2}\right)$ that can be calculated from Eq. (3). At the beginning of the oxidation stage, the product gas is discharged at $\mathrm{T}_{\text {gin, }, \mathrm{r}}$, which is the temperature of the solids located closest to the exit. This discharge of low temperature $\mathrm{N}_{2}$ takes place until the heat exchange front $\left(\mathrm{e}_{2}\right)$, marked as the transition $\mathrm{T}_{1} / \mathrm{T}_{\text {gin, },}$, reaches the reactor exit. During the period of time needed for the heat exchange front $\left(e_{1}\right)$ to reach the end of the bed, the product gas is released at $T_{1}$. During the rest of the Ni oxidation period until complete oxidation of the solids bed has taken place, the flue gas is released at the maximum temperature of the reaction front $\left(T_{\max }\right)$, which is a suitable temperature to be fed into the gas turbine of a combined cycle for power generation, as indicated in Fig. 1. As $\mathrm{T}_{\max }$ is lower than the nominal inlet temperature of the gas turbine $\left(1400-1450^{\circ} \mathrm{C}\right)$, a small flow of natural gas and air can be used to reach the optimum temperature for the gas turbine, at the expense of a minor amount of carbon leakage [22, 54].

As pointed out above, one of the disadvantages of this mode of operation with heat transfer fronts moving ahead of reaction fronts is that at the end of the oxidation stage, the bed is left at the temperature of the inlet gas $\left(\mathrm{T}_{\text {gin,o }}\right)$, (see Fig. $3, \mathrm{t}=\mathrm{t}_{3}$ ). This temperature is too low to initiate the next reaction stage in which a new reduction of $\mathrm{NiO}$ to Ni must take place. For this reason, an additional heat exchange stage (Fig. 4) is 
required so that part of the sensible heat from the product gas is used to raise the temperature of the oxidized bed up to a sufficient value ( $T_{s 1}$ in Fig. 2) to permit a multicycle operation. The solids bed will gradually be heated from $T_{\text {gin,o }}$ to $T_{\mathrm{s} 1}$ as the heat exchange front (indicated in Fig. 4 as the transition $T_{\mathrm{s} 1} / \mathrm{T}_{\text {gin,o }}$ ) moves forward during the operation. The nitrogen, which is discharged at $\mathrm{T}_{\text {gin,o }}$, will be re-compressed and subsequently recirculated to other reactors that are performing in oxidation stages in order to dilute the content of $\mathrm{O}_{2}$ in their feed so as to regulate the temperature in the oxidation front (as explained above).

In light of the discussion above and as explained in the design case study (see below), every reactor in the CLC system proposed in this work undertakes five different reaction and/or heat exchange stages. During the first stage (stage A, as represented in Fig. 2), a stream of methane (1) is oxidized to $\mathrm{CO}_{2}$ and $\mathrm{H}_{2} \mathrm{O}$ by the Ni-based oxygen carrier contained in the packed bed. In the second stage (stage B, as indicated in Fig. 3, $\mathrm{t}=\mathrm{t}_{1}$ ), a mixture of air and recycled nitrogen (stream 7) is fed by the part of the bed which has been left after the reduction stage at a higher temperature $\left(T_{1}\right)$ in order to carry out the oxidation of the oxygen carrier. This stage will last until the heat exchange front $\left(\mathrm{e}_{1}\right)$ arrives at the reactor exit, when the flue gas is about to be released at the maximum temperature $\left(\mathrm{T}_{\max }\right)$. The part of the bed that has not been crossed by the reaction front will be left in its reduced form (as $\mathrm{NiO}$ ) and at the maximum temperature $\left(\mathrm{T}_{\max }\right)$. The rest of the bed, as indicated above, will already have been oxidized and left at the inlet gas temperature $\left(\mathrm{T}_{\text {gin,o }}\right)$. The recycled nitrogen must be cooled down (to $\left.\mathrm{T}_{\text {gin,o }}\right)$ in order to moderate the maximum temperature in the reaction front (Eq. 5). The sensible heat extracted from this operation can be used in the steam cycle part of the combined cycle. The cold non-recirculated nitrogen is fed into a different reactor that is operating in the third stage, as described below. In the third stage $(\mathrm{C}$, as represented in 
Fig. 3, $\mathrm{t}=\mathrm{t}_{2}$ ), the oxidation of the solids bed is continued by feeding in a mixture of air and nitrogen (stream 12 in Fig. 3) at low temperature and high pressure. The flue gas, which is released at the maximum temperature of the reaction front $\left(\mathrm{T}_{\max }\right)$, is used to drive a gas turbine of a combined cycle as indicated above. A large fraction of the exhaust gas from the HRSG of the $\mathrm{N}_{2}$-based combined cycle must be recirculated and re-compressed into the reactor inlet. This is a similar operation to the flue gas recirculation (FGR) options being considered for large scale NGCC to increase the concentration of $\mathrm{CO}_{2}$ in flue gases before they enter postcombustion capture systems $[55,56]$. In order to minimize the recirculation ratio in this third stage $\mathrm{C}$, the streams of nitrogen at high pressure and moderate temperature produced in the other oxidation stages and not required there are also fed into the inlet of the air reactor. In the fourth stage ( $\mathrm{D}$, as represented in Fig. $\left.3, \mathrm{t}=\mathrm{t}_{3}\right)$ the complete oxidation of the solids bed is attained by feeding in a mixture of air and recycled nitrogen (stream 17). However, the product gas (stream 18) is fed into a reactor, that is operating in the fifth stage E (already oxidized and initially cold as indicated in Fig. 4) to raise its temperature up to a sufficient value $\left(\mathrm{T}_{\mathrm{s} 1}\right)$ so that another subsequent reduction stage can be initiated, permitting a multicycle operation. A part of the sensible heat of stream (18) may be removed in order to reduce the temperature of this stream from $T_{\max }$ to $T_{s 1}$, before it is fed into stage (E). The solids bed is progressively heated from $T_{\text {gin,o }}$ to $T_{\mathrm{s} 1}$ as the heat exchange front (indicated in Fig. 4 as the transition $T_{\mathrm{s} 1} / \mathrm{T}_{\text {gin,o }}$ ) moves forward during the stage (E). The nitrogen, which is discharged at $\mathrm{T}_{\text {gin,o }}$, is subsequently divided into two streams: one fraction (stream 20) is recirculated to stage (D) to dilute the content of $\mathrm{O}_{2}$ at the inlet of the reactor in order to regulate the temperature in the oxidation front (as explained above), and the rest (stream 19) is fed into a reactor operating in stage (C) for the same purpose. 


\section{Case study}

In the previous section, the performance of each single reactor that integrates the CLC fixed-bed configuration has been qualitatively described in a sequence of five stages necessary to carry out the reactions involved and satisfy the energy requirements of the process. In the following paragraphs, a characteristic design for a reference flow of 20 $\mathrm{kg} / \mathrm{s}$ of methane, which is comparable to current reference NGCC systems, is examined. For this purpose, a $\mathrm{NiO} / \mathrm{MgAl}_{2} \mathrm{O}_{4}$ oxygen carrier has been chosen. $\mathrm{MgAl}_{2} \mathrm{O}_{4}$ has been studied by several authors as an alternative support to alumina [26, 28, 57], because the addition of $\mathrm{Mg}$ to the support limits the sintering of $\mathrm{NiO}$ and stabilizes the $\mathrm{Ni}^{2+}$ in the solid phase. As a result, the Ni-based carrier shows a high stability after multiple reduction and oxidation cycles even at temperatures above $1300{ }^{\circ} \mathrm{C}$ [58]. The specific oxygen carrier used in this work consists of 60 wt. $\% \mathrm{NiO}$ over $\mathrm{MgAl}_{2} \mathrm{O}_{4}$ with a pellet size of $0.01 \mathrm{~m}$. Assuming a void fraction of $50 \%$, a bed density of $1700 \mathrm{~kg} / \mathrm{m}^{3}$ is obtained when the oxygen carrier is completely oxidized. A pressure of 20 bar has been chosen for each stage of the process because this is the operating pressure that leads to the highest efficiency in a gas turbine [21]. Table 1 summarizes the input operating conditions chosen for the case study and Table 2 indicates the temperature, pressure, flow rate and composition of the main inlet and outlet flows of the reactors represented in Figs. 2-4.

It is assumed that the packed bed at the beginning of the reduction stage (A) is completely oxidized and a significant part of the solids is at a very high temperature $\left(\mathrm{T}_{\mathrm{s} 1}\right.$ in Fig. $2, \mathrm{t}=\mathrm{t}_{0}$ ), as a result of a previous oxidation stage (which should be the end of the fifth stage E in each cycle). The type of Ni-based carriers considered in this work have a great tendency to react with methane at operating temperatures higher than $600{ }^{\circ} \mathrm{C}$, with the almost complete conversion of the fuel gas to $\mathrm{CO}_{2}$ and $\mathrm{H}_{2} \mathrm{O}$ [59], as shown in Fig. 5. 
A temperature of $1300{ }^{\circ} \mathrm{C}$ was chosen for $\mathrm{T}_{\mathrm{s} 1}$, because it is the maximum allowable temperature that will avoid the loss of solids reactivity and agglomeration in the $\mathrm{NiO} / \mathrm{MgAl}_{2} \mathrm{O}_{4}$ carrier. At these conditions, very fast reduction kinetics and total fuel conversion will be ensured from the very beginning of the operation. The methane for the reduction will be supplied at 20 bar and $150^{\circ} \mathrm{C}$ (stream 1 in Fig. 2) through the part of the reactor where the solids are at $1300{ }^{\circ} \mathrm{C}$. The recirculation of a part of the product gas (stream 5 in Fig. 2) will allow the mass flow fed in at the reduction stage (stream 2 in Fig. 2) to be increased, which will accelerate the advance of the heat exchange fronts through the bed (expressed as $e_{1}$ and $e_{2}$ in Fig. 2). A recirculation ratio of around 0.6 (calculated as the ratio between the volumetric flows of stream 5 and stream 3 in Fig. 2) will make the reaction front (r) advance only approximately 1.2 times faster than the heat exchange front $\left(\mathrm{e}_{2}\right)$. This will allow the solids bed to be completely reduced by starting the reduction stage with around $32 \%$ of the bed at $1300^{\circ} \mathrm{C}\left(\mathrm{T}_{\mathrm{s} 1}\right)$ and the remaining $68 \%$ of the bed at $150{ }^{\circ} \mathrm{C}\left(\mathrm{T}_{\mathrm{s} 2}\right)$. The reduced distance between fronts $(\mathrm{r})$ and $\left(\mathrm{e}_{1}\right)$ in this reaction stage will be at the expense of a higher drop in temperature in the reduction front $\left(\Delta \mathrm{T}_{\max }\right)$, because there will be smaller mass of solids at $\mathrm{T}_{\mathrm{s} 1}$ to supply the necessary heat to carry out the endothermic reduction of $\mathrm{NiO}$ to $\mathrm{Ni}$ (see Fig. 2). Fig. 6 represents the relationship between these variables for the materials and conditions chosen in this design case.

Under the operating conditions represented in Table 1, a drop in temperature in the reduction front of about $730{ }^{\circ} \mathrm{C}$ (see Eq. 4 and Fig. 6) is obtained. This means that the reduced solids will be left behind the reaction front at $570{ }^{\circ} \mathrm{C}\left(\mathrm{T}_{1}\right.$ in Fig. 2), which is sufficiently high to initiate a rapid oxidation of the Ni-based carrier in the following reaction stage. Since the operating conditions of the reduction stage have been chosen to make both the reaction front, $r$, and the heat exchange front, $e_{2}$, (marked as the transition 
$\mathrm{T}_{\mathrm{s} 1} / \mathrm{T}_{\mathrm{s} 2}$ in Fig. 2) reach the reactor exit at the same time, the product gas (stream 14) will be released at $150{ }^{\circ} \mathrm{C}\left(\mathrm{T}_{\mathrm{s} 2}\right)$, which corresponds to the initial temperature of the solids closest to the reactor exit. Once the oxygen carrier has been completely reduced, $22 \%$ of the solids bed is left at $570{ }^{\circ} \mathrm{C}\left(\mathrm{T}_{1}\right)$, whereas the rest of the bed $(78 \%)$ has been cooled down to $150^{\circ} \mathrm{C}\left(\mathrm{T}_{\text {gin, }}\right)$, which is the temperature of the gas fed into the reactor.

Once the oxygen carrier has been completely reduced, the oxidation stage represented in Fig. $3\left(\mathrm{t}=\mathrm{t}_{0}\right)$ is initiated, where a part of the bed is oxidized by feeding in a mixture of air (stream 6 in Fig. 3) and recycled nitrogen (stream 10 in Fig. 3). A flow of air of about $3.96 \mathrm{kmol} / \mathrm{s}$, which is supplied by a compressor at 20 bar and $150{ }^{\circ} \mathrm{C}$, is introduced through the part of the reactor where the solids are at the highest temperature $\left(570{ }^{\circ} \mathrm{C}\right.$, $\mathrm{T}_{1}$ in Fig. 3). This temperature is sufficiently high to ensure from the very beginning of the operation the complete conversion of $\mathrm{O}_{2}$ in a very narrow oxidation front. The main concern during the oxidation of the bed is the management of the heat released from the oxidation of $\mathrm{Ni}$ to $\mathrm{NiO}\left(\Delta \mathrm{H}_{298 \mathrm{~K}}=-239 \mathrm{~kJ} / \mathrm{mol} \mathrm{Ni}\right)$. In order to regulate the temperature in the reaction front and limit the maximum temperature $\left(\mathrm{T}_{\max }\right)$ to $1300^{\circ} \mathrm{C}$, it is necessary to sufficiently separate the advance of the reaction front (r, in Fig. 3) and the heat exchange front ( $\mathrm{e}_{1}$, in Fig. 3). As can be seen in Fig. 7, the ratio between the reaction and heat exchange front $\left(\mathrm{u}_{\mathrm{r}} / \mathrm{u}_{\mathrm{e}}\right)$ depends to a large extent on the contents of $\mathrm{Ni}$ and $\mathrm{O}_{2}$ in the solids bed and in the gas feed, respectively. Since the oxygen carrier chosen for this case study contains a high percentage of active phase (60 wt.\%), a high dilution of $\mathrm{O}_{2}$ in the feed is required.

The effect of the recirculation ratio on the dilution of $\mathrm{O}_{2}$ in the feed and on the increase of temperature in the oxidation front (see Eq. 5) is represented in Fig. 8. As can be seen, recirculation ratios higher than 0.85 are required to limit the increase of temperature in the reaction front to below $800{ }^{\circ} \mathrm{C}$, which means a decrease in the $\mathrm{O}_{2}$ content of the feed 
to below 4 vol.\%. A higher recirculation ratio reduces the $\mathrm{u}_{\mathrm{r}} / \mathrm{u}_{\mathrm{e}}$ ratio and, as a result, a larger temperature plateau will be formed (fraction of the bed at maximum temperature, $\mathrm{T}_{\max }$, in Fig. 3). Furthermore, the heat released from the reaction front will be absorbed by a growing quantity of solids located between both fronts, and therefore the resulting maximum temperature of the outlet gas will be lower, which will have a negative effect on the efficiency of the process.

A recirculation ratio of around 0.78 (calculated as the ratio between the volumetric flows of stream 10 and stream 8) makes it possible to dilute the $\mathrm{O}_{2}$ in stream 7 down to 5.4 vol. $\%$. In these conditions, the heat exchange front $\left(\mathrm{e}_{1}\right)$ will advance approximately 3 times faster than the reaction front (r), and the maximum increase of temperature in the reaction front will be around $1150{ }^{\circ} \mathrm{C}$. Since the gas arrives at the oxidation front at its inlet temperature $\left(\mathrm{T}_{\text {gin,o }}\right)$, this will need to be low (approximately $150{ }^{\circ} \mathrm{C}$ ) in order to keep the maximum temperature during the operation below $1300{ }^{\circ} \mathrm{C}$. A heat exchanger will then be required to remove the excess of heat from the compressed air (stream 6) before it is mixed with the recycled nitrogen and fed into stage (B) represented in Fig. 3, $\mathrm{t}=\mathrm{t}_{1}$ ). Under these conditions, a product gas of $14.50 \mathrm{kmol} / \mathrm{s}$ (stream 8), mainly composed of nitrogen, will be discharged at the beginning of stage (B) at $150{ }^{\circ} \mathrm{C}$, which is the temperature of the solids located closest to the reactor exit $\left(T_{\text {gin, },}\right)$. This will be until the heat exchange front $\left(\mathrm{e}_{2}\right)$ reaches the exit, which corresponds approximately to $80 \%$ of duration of the oxidation stage (B). During the rest of stage (B), the nitrogen will leave the reactor at $570{ }^{\circ} \mathrm{C}\left(\mathrm{T}_{1}\right.$ in Fig. 3). As explained above, the first oxidation stage (B) will finish when the heat exchange front $\left(\mathrm{e}_{1}\right)$ arrives at the reactor exit and the flue gas is close to being discharged at $\mathrm{T}_{\max }$ (see Fig. 3). At that moment, $33 \%$ of the bed will have been oxidized, and left at the inlet gas temperature $\left(150^{\circ} \mathrm{C}, \mathrm{T}_{\text {gin,o }}\right.$ in Fig. 
3). The rest of the bed, that has not been reached by the reaction front (r), will remain as $\mathrm{NiO}$ and at the maximum temperature $\left(1300^{\circ} \mathrm{C}\right)$.

The oxidation of the bed of solids will continue during stage $(\mathrm{C})$, while the flue gas leaves the reactor at $1300{ }^{\circ} \mathrm{C}$ (stream 13 in Fig. $3, \mathrm{t}=\mathrm{t}_{2}$ ), and is subsequently fed into a gas turbine for power generation. A large fraction of the cooled $\mathrm{N}_{2}$ exhaust gas from the combined cycle will be recirculated and recompressed into the reactor inlet. Moreover, the streams of nitrogen at high pressure and moderate temperature produced in the stage (B) and stage (E) but which are not required there, streams (9) and (19), respectively, will also be fed into the inlet of the stage (C) in order to minimize the need for $\mathrm{N}_{2}$ to be recirculated during the operation. The total flow introduced into the reactor will be about $24.28 \mathrm{kmol} / \mathrm{s}$ (stream 12 in Fig. 3) whilst the nitrogen obtained at the outlet will be around $22.96 \mathrm{kmol} / \mathrm{s}$ (stream 13). At the conditions chosen for this case study, with the excess of nitrogen from stage (B) $(3.13 \mathrm{kmol} / \mathrm{s}$, stream 9) and the excess of nitrogen from stage (E) $(1.31 \mathrm{kmol} / \mathrm{s}$, stream 19$)$, that will be discussed below, the flow of nitrogen required from the exhaust gas of the combined cycle (stream 15) will be about $13.56 \mathrm{kmol} / \mathrm{s}$. In order to maximize the power generated in the gas turbine, a topping cycle can also be introduced into the system by burning an additional stream of natural gas with air at 20 bar. A feed of $0.25 \mathrm{kmol} / \mathrm{s}$ of methane burned with $2.44 \mathrm{kmol} / \mathrm{s}$ of air will increase the temperature of the product gas up to $1450{ }^{\circ} \mathrm{C}$, which is inside the typical range of inlet temperatures of gas turbines.

As mentioned above, the final oxidation stage (D), has been designed to complete the oxidation of the solids in the reactor, while the high-temperature product gas is fed to an oxidized and cooled bed (resulting from stage D) in order to raise its temperature from $150^{\circ} \mathrm{C}$ to $\mathrm{T}_{\mathrm{s} 1}$ (see Fig. 4) so that new reduction stage can be initiated, i.e. stage (A). Thus, an overall heat balance will define the heat requirements for carrying out a new 
stage (A) and will allow the transition point between stage (C) and stage (D) to be established. Under the conditions of this reference case, the stage (D) will begin when nearly $85 \%$ of the solids in the reactor of Fig. $3\left(t=t_{2}\right)$ has been oxidized. A feed of 6.41 $\mathrm{kmol} / \mathrm{s}\left(5.4 \mathrm{vol} . \%\right.$ of $\left.\mathrm{O}_{2}\right)$ will be introduced at $150{ }^{\circ} \mathrm{C}$ and 20 bar and a flow of 6.06 $\mathrm{kmol} / \mathrm{s}$ of nitrogen will be discharged at $1300^{\circ} \mathrm{C}$ (see Fig. $3, \mathrm{t}=\mathrm{t}_{3}$ ). Subsequently, this stream (18) will enter the reactor in stage (E) and, as the heat exchange front (e) moves through the bed, the solids left behind will increase their temperature from $150{ }^{\circ} \mathrm{C}$ to $1300^{\circ} \mathrm{C}$ ( $\mathrm{T}_{\mathrm{s} 1}$ in Fig. 4).

At the outlet of stage (E), the $\mathrm{N}_{2}$ will leave the reactor cooled down to $150{ }^{\circ} \mathrm{C}$, and then it will be recompressed and subsequently divided into two streams: $4.75 \mathrm{kmol} / \mathrm{s}$ (stream 20) will be recirculated to stage (D), where it will be used to the content of $\mathrm{O}_{2}$ to 5.4 vol.\%, whilst $1.31 \mathrm{kmol} / \mathrm{s}$ (stream 19) will be introduced into stage (C) for the same purpose. Stage (E) will end when $32 \%$ of the bed has reached $1300{ }^{\circ} \mathrm{C}$, which is the fraction of solids at high temperature required to start the subsequent reduction stage (A) and initiate a new complete cycle.

In a continuous process, all the stages described above must be carried out in a system of packed-bed reactors dynamically operated in a cyclic manner. It is necessary to ensure the production of a continuous stream of nitrogen at high pressure and high temperature for its expansion in a gas turbine, as indicated in the basic scheme of Fig. 1. This hot $\mathrm{N}_{2}$ gas must be produced at an approximately constant temperature and mass flow rate in order to avoid thermal and mechanical stress in the gas turbine expander [46]. However, each of the five stages described above may have different durations in order to accommodate very different inlet gas flows (see Table 2) reasonable gas velocities and pressure drops among the reactors of the system. In order for these process requirements to be compatible, a larger number of reactors is needed, operating 
in synchronized mode, as in the case of other large-scale swing reaction systems. On the other hand, the total number of reactors and the volume of each reactor needs to be kept to a minimum in order to minimize the cost of the equipment and materials. Taking into consideration these points, a reference design case is discussed in the following paragraphs that gives the size and minimum number of reactors required for a complete CLC continuous system.

The geometry of a single reactor and the duration decided to carry out each stage of the CLC process must accommodate the inlet gas flows so that the superficial gas velocities during the operation are reasonable and therefore, the pressure drop per stage is moderate. Shorter cycle durations lead to smaller cross-sectional areas to convert the same amount of gas fed into the system. Moreover, larger reactor lengths combined with smaller diameters (i. e. lower L/D ratios) also reduce the total area required. However, these conditions cause higher pressure drops, resulting in an increase of the energy needed to re-compress the gas streams involved in the process. A minimum duration of about 10 minutes and a maximum pressure drop along the bed of about 1 bar $(\Delta \mathrm{P} / \mathrm{P}<5 \%)$ can be considered as reasonable values to fulfill each single stage of the process. For an inlet flow of $20 \mathrm{~kg} / \mathrm{s}$ of methane fed into the reduction stage and taking into account the operating conditions and reactor characteristics listed in Table 1, a cross-sectional area of around $25 \mathrm{~m}^{2}$ was obtained for carrying out the reduction stage, which means that the reactor diameter will be of the order of $5.6 \mathrm{~m}$. Once the reactor geometry has been calculated for the reduction stage (A), the number of reactors working in parallel required to accomplish the remaining stages can be estimated. Taking into account the inlet flow rates, the operating conditions described in Table 2 and the operating constraints mentioned above (maximum pressure drop and minimum cycle duration), two reactors for stage (B), three reactors for stage (C), one reactor for 
stage (D) and one reactor for stage (E) will be required, which means that a total cycle time of about 80 minutes will be needed. The operational diagram of the CLC configuration proposed is represented in Fig. 9, which is similar to other configurations recently published for SER and CLC applications [60-63].

The overall flow diagram of the proposed CLC configuration (see Fig. 10) comprises some elements that are common to conventional natural gas combined cycles (NGCC), such as the air compressor (101), the gas turbine (111), the heat recovery steam generator (HRSG, 112 in Fig. 10) and the compressor (113) for the $\mathrm{N}_{2}$ flue gas recycle, which is equivalent to the proposed flue gas recycle for standard NGCC to increase the concentration of $\mathrm{CO}_{2}$ in the flue gases before they enter the postcombustion capture systems [55, 56]. Additional elements must be included in the system to ensure adequate operating conditions in each stage. Blowers (104) and (107) are used to recompress the recycled streams of $\mathrm{CO}_{2}$ with steam and $\mathrm{N}_{2}$, respectively. Since the feed for these blowers must be introduced at a low temperature, the excess of sensible heat must be previously removed in the heat exchangers (103) and (106), respectively. Moreover, heat exchangers (100), (102), (105), (108) and (114) are required to condition the temperature of the inlet streams of methane and air, and the temperature of the inner recirculations incorporated into the system.

A valve set-up is necessary to synchronize the operation of the eight reactors and obtain a continuous flow of product gas at high temperature and high pressure suitable for expansion in the gas turbine (111) for power generation. For a specific instant (represented in Fig. 9 by a dotted line), the reactors that form the CLC configuration (see Fig. 10) are performing as follows: reactor (1) as stage (A), reactor (2) as stage (E), reactor (3) as stage (D), reactors (4), (5) and (6) as stage (C), and finally, reactors (7) and (8) as stage (B). At this point, valve (10) is open, while valve (17) is closed. This 
allows the methane required for stage (A) to be introduced, while the entrance of air into reactor (1) is avoided. Downstream of reactor (1) (right side), valves (14), (15), and (20) are open in order to regulate the fraction of the $\mathrm{CO}_{2}$ and $\mathrm{H}_{2} \mathrm{O}$ produced that is destined for transport and storage and the fraction that is recirculated. Furthermore, valve (38) and valve (34) are open in order to allow air to be fed to reactor (3) for the stage (D) and allow the flow of hot nitrogen from reactor (3) to reactor (2), that perform as stages (D) and (E), respectively. Downstream of reactor (2) (right side), valve (27) is open, while valves (25) and (26) are closed, because the outlet $\mathrm{N}_{2}$ must be recirculated to other reactors (via blower 107). The process flow diagram is represented in Fig. 10, where the positions of the valves that form the overall set-up system for a snapshot of the process is detailed (white valves are open and black valves are closed for this specific point in time).

The position of the valves changes every 10 minutes following the sequence of the reaction stages indicated in Fig. 9. In a large scale system, additional short rinse/purge stages between the main reaction stages may be required, as it is the case in swing operation systems, but here they have been omitted for simplicity. The full system of Fig. 10 operates continuously by feeding pressurized air and methane, while the combustion products are obtained separately, as happens in Fig. 1, that is, a $\mathrm{N}_{2}$ rich stream, which is continuously expanded in the gas turbine and cooled down to generate steam (combined cycle), and a pressurized stream of rich $\mathrm{CO}_{2}$. Although the analysis of the energy efficiency and the evaluation of the cost of this configuration are beyond the scope of this work, there is clearly an opportunity for a competitive $\mathrm{CO}_{2}$ capture system to be developed based on this scheme. The possibility to operate at high pressures opens the door to high efficiency systems using existing natural gas combined cycles (NGCC). The reactor volume is relatively modest and can be made smaller by reducing cycle 
times. Moreover, the adiabatic character of the reactors and the lack of heat exchange operations into the beds facilitate the construction. In contrast, the cost of the system can escalate due to the large number of high temperature and pressure switching valves, the high pressure reactors and the cost of highly reactive oxygen carrier material that must retain good reactivity after many cycles. In any case, chemical looping combustion in fixed beds is receiving increasing attention in the literature and some of these questions could be elucidated in future works.

\section{Conclusions}

Fixed-bed configurations using Ni-based materials can be considered as a valid alternative to carry out the chemical looping combustion of methane at high pressure to overcome the characteristic problems of high pressure fluidized bed concepts, including trace emissions of hazardous metals. Simple reactor models to quantify the temperature profiles during the different reaction stages in fixed beds reveal that the increase of temperature in the $\mathrm{Ni}$ oxidation fronts can be moderated by the introduction of cooled nitrogen recycles into the different oxidation stages of the process. In these conditions, oxygen carriers with higher $\mathrm{Ni}$ content $(\geq 60$ wt.\%) can be used, resulting a more compact reactor designs. Likewise, the recirculation of $\mathrm{CO}_{2}$ and $\mathrm{H}_{2} \mathrm{O}$ improves the heat management during the $\mathrm{NiO}$ reduction stage. The displacement of the reaction and heat

transfer fronts can be controlled with reasonable values of flue gas recycles, allowing the reduction stage to be initiated with a lower fraction of solids at high temperature. Consequently, a higher proportion of the heat generated during the Ni oxidation stages can be used for power generation by expanding the high temperature pressurized $\mathrm{N}_{2}$ in a gas turbine. A full process scheme involving eight reactors $(8 \mathrm{~m}$ long and with an inner diameter of $5.6 \mathrm{~m}$ ) switching every ten minutes between five different reactions and heat transfer stages has been shown to allow a continuous operation of the CLC system 
for natural gas at high pressure. The preliminary design of the concept for a $20 \mathrm{~kg} / \mathrm{s}$ of methane has made it possible to identify reasonable operating conditions for the eight reactors that make up the complete $\mathrm{CO}_{2}$ capture process, and has confirmed the technical feasibility and large potential of fixed-bed reactor technology when applied to chemical looping combustion systems.

\section{Acknowledgements}

This work is financed under the $\mathrm{R}+\mathrm{D}$ Spanish National Program organised by the Spanish Ministry of Economy and Competitiveness under project ENE2012-37936C02-02 and by CSIC 201280E017.

\section{Nomenclature}

$\mathrm{c}_{\mathrm{pi}} \quad$ specific heat capacity of component $\mathrm{i}, \mathrm{kJ} / \mathrm{mol}^{\circ} \mathrm{C}$

$\Delta \mathrm{H} \quad$ enthalpy of the reaction, $\mathrm{kJ} / \mathrm{mol}$

$\mathrm{M}_{\mathrm{i}} \quad$ molecular weight of component $\mathrm{i}, \mathrm{kg} / \mathrm{mol}$

P pressure, bar

t time, $s$

$\mathrm{T}_{\mathrm{g}, \text { in }} \quad$ inlet gas temperature, ${ }^{\circ} \mathrm{C}$

$\mathrm{T}_{\max } \quad$ maximum temperature, ${ }^{\circ} \mathrm{C}$

$\mathrm{T}_{\mathrm{s} 0} \quad$ initial temperature of bed reactor, ${ }^{\circ} \mathrm{C}$

$\Delta \mathrm{T}_{\max }$ maximum adiabatic temperature increase, ${ }^{\circ} \mathrm{C}$

$\mathrm{u}_{\mathrm{e}} \quad$ heat exchange front velocity, $\mathrm{m} / \mathrm{s}$

$\mathrm{u}_{\mathrm{g}} \quad$ gas velocity, $\mathrm{m} / \mathrm{s}$

$\mathrm{u}_{\mathrm{r}} \quad$ reaction front velocity, $\mathrm{m} / \mathrm{s}$

$\mathrm{x}_{\mathrm{i}} \quad$ weight fraction of component $\mathrm{i}$, dimensionless

Greek letters 


$$
\begin{array}{ll}
\rho_{\mathrm{i}} & \text { density of component } \mathrm{i}, \mathrm{kg} / \mathrm{m}^{3} \\
\varepsilon & \text { porosity, dimensionless } \\
\varphi & \text { stoichiometric factor, dimensionless }
\end{array}
$$

\section{References}

[1] Metz B, Davidson O, de Coninck H, Loos M, Meyer L. IPCC Special Report on Carbon Dioxide Capture and Storage. Prepared by Working Group III of the Intergovernmental Panel on Climate Change. Cambridge University Press, Cambridge, United Kingdom and New York, NY, USA, 2005. p. 442.

[2] Ishida M, Jin HG. A new advanced power-generation system using chemicallooping combustion. Energy 1994; 19: 415-422.

[3] Anheden M, Svedberg G. Exergy analysis of chemical-looping combustion systems. Energy Convers Mgmt 1998; 39: 1967-1980.

[4] Lyngfelt A, Leckner B, Mattisson T. A fluidized-bed combustion process with inherent $\mathrm{CO}_{2}$ separation; application of chemical-looping combustion. Chem Eng Sci 2001; 56: 3101-3113.

[5] Johansson E, Lyngfelt A, Mattisson T, Johnsson F. Gas leakage measurements in a cold model of an interconnected fluidized bed for chemical-looping combustion. Powder Technology 2003; 134: 210-217.

[6] Son SR, Kim SD. Chemical-looping combustion with $\mathrm{NiO}$ and $\mathrm{Fe}_{2} \mathrm{O}_{3}$ in a thermobalance and circulating fluidized bed reactor with double loops. Ind Eng Chem Res 2006; 45: 2689-2696.

[7] Mattisson T, García-Labiano F, Kronberger B, Lyngfelt A, Adánez J, Hofbauer H. Chemical-looping combustion using syngas as fuel. Int J Greenh Gas Con 2007; 1: 158169.

[8] Fan LS. Chemical Looping Systems for Fossil Fuel Energy Conversions, A John Wiley \& Sons, Inc., Publication, Hoboken, New Jersey, USA; 2010. 
[9] Adanez J, Abad A, Garcia-Labiano F, Gayan P, de Diego L.F. Progress in Chemical-Looping Combustion and Reforming technologies. Prog Energ Combust 2012; 38: 215-282.

[10] Ishida M, Yamamoto M, Ohba T. Experimental results of chemical-looping combustion with $\mathrm{NiO} / \mathrm{NiAl}_{2} \mathrm{O}_{4}$ particle circulation at 1200 degrees C. Energy Convers Mgmt 2002; 43: 1469-1478.

[11] Kronberger B, Lyngfelt A, Löffler G, Hofbauer H. Design and fluid dynamic analysis of a bench-scale combustion system with $\mathrm{CO}_{2}$ separation-chemical-looping combustion. Ind Eng Chem Res 2005; 44: 546-556.

[12] Abad A, Mattisson T, Lyngfelt A, Ryden M. Chemical-looping combustion in a $300 \mathrm{~W}$ continuously operating reactor system using a manganese-based oxygen carrier. Fuel 2006; 85: 1174-1185.

[13] Johansson E, Mattisson T, Lyngfelt A. A $300 \mathrm{~W}$ laboratory reactor system for chemical-looping combustion with particle circulation. Fuel 2006; 85:1428-1438.

[14] de Diego LF, García-Labiano F, Gayán P, Celaya J, Palacios JM, Adánez J. Operation of a $10 \mathrm{kWth}$ chemical-looping combustor during $200 \mathrm{~h}$ with a $\mathrm{CuO}-\mathrm{Al}_{2} \mathrm{O}_{3}$ oxygen carrier. Fuel 2007; 86: 1036-1045.

[15] Lyngfelt A, Thunman H. Construction and $100 \mathrm{~h}$ operational experience of a 10kW chemical-looping combustor. Carbon Dioxide Capture for Storage in Deep Geologic Formations. 625-645. Elsevier, ISBN: 978-008044570-0, DOI: 10.1016/B978008044570-0/50122-7, 2005.

[16] Adanez J, Gayan P, Celaya J, de Diego LF, Garcia-Labiano F, Abad, A. Chemical looping combustion in a $10 \mathrm{~kW}\left(\right.$ th) prototype using a $\mathrm{CuO} / \mathrm{Al}_{2} \mathrm{O}_{3}$ oxygen carrier: Effect of operating conditions on methane combustion. Ind Eng Chem Res 2006; 45: 60756080 .

[17] Linderholm C, Abad A, Mattisson T, Lyngfelt A. 160h of chemical-looping combustion in a $10 \mathrm{~kW}$ reactor system with a NiO-based oxygen carrier. Int J Greenh Gas Con 2008; 2: 520- 530. 
[18] Lyngfelt A. Oxygen Carriers for Chemical Looping Combustion - $4000 \mathrm{~h}$ of Operational Experience. Oil \& Gas Science and Technology - Rev. IFP Energies nouvelles 66, 161-172, 2011.

[19] Forero CR, Gayán P, de Diego LF, Abad A, García-Labiano F, Adánez, J. Syngas combustion in a 500-Wth Chemical-Looping Combustion system using an impregnated Cu-based oxygen carrier. Fuel Process Technol 2009; 90: 1471-1479.

[20] Kolbitsch P, Bolhàr-Nordenkampf J, Pröll T, Hofbauer H. Operating experience with chemical looping combustion in a $120 \mathrm{~kW}$ dual circulating fluidized bed (DCFB) unit. Int J Greenh Gas Con 2010; 4: 180-185.

[21] Brandvoll Ø, Bolland $\mathrm{O}$. Inherent $\mathrm{CO}_{2}$ capture using chemical looping combustion in a natural gas fired power cycle. J Eng Gas Turb Power 2004; 126: 316-21.

[22] Naqvi R, Bolland O. Multi-stage chemical looping combustion (CLC) for combined cycles with $\mathrm{CO}_{2}$ capture. Int J Greenh Gas Con 2007; 1: 19-30.

[23] Xiao R, Song Q, Song M, Lu Z, Zhang S, Shen, L. Pressurized chemical-looping combustion of coal with an iron ore-based oxygen carrier. Combust Flame 2010; 157: 1140-1153.

[24] Bischi A, Langorgen O, Saanum I, Bakken J, Seljeskog M, Bysveen M, Morin X, Bolland O. Design study of a $150 \mathrm{~kW}_{\text {th }}$ double loop circulating fluidized bed reactor system for chemical looping combustion with focus on industrial applicability and pressurization. Int J Greenh Gas Con 2011; 5: 467-474.

[25] Xiao R, Chen L, Saha C, Zhang S, Bhattacharya S. Pressurized chemical-looping combustion of coal using an iron ore as oxygen carrier in a pilot-scale unit. Int J Greenh Gas Con 2012; 10: 363-373.

[26] Villa R, Cristiani C, Groppi G, Lietti L, Forzatti P, Cornaro U, Rossini S. Ni based mixed oxide materials for $\mathrm{CH}_{4}$ oxidation under redox cycle conditions. J Mol Catal AChem 2003; 204: 637-646.

[27] Cho P, Mattisson T, Lyngfelt A. Comparison of iron-, nickel-, copper- and manganese-based oxygen carriers for chemical-looping combustion. Fuel 2004; 83: 1215-1225. 
[28] Mattisson T, Johansson M, Lyngfelt A. The use of $\mathrm{NiO}$ as an oxygen carrier in chemical looping combustion. Fuel 2006; 85: 736-747.

[29] Zafar Q, Mattisson T, Gevert B. Integrated Hydrogen and Power Production with CO2 Capture Using Chemical-Looping Reforming-Redox Reactivity of Particles of $\mathrm{CuO}, \mathrm{Mn}_{2} \mathrm{O}_{3}, \mathrm{NiO}$, and $\mathrm{Fe}_{2} \mathrm{O}_{3}$ Using $\mathrm{SiO}_{2}$ as a Support. Ind Eng Chem Res 2005; 44: 3485-3496.

[30] Rydén M, Lyngfelt A. Using steam reforming to produce hydrogen with carbon dioxide capture by chemical-looping combustion. Int J Hydrogen Energ 2006; 31: 12711283.

[31] Ishida M, Jin H. A novel chemical-looping combustor without NOx formation. Ind Eng Chem Res 1996; 35: 2469-2472.

[32] Gayán P, Dueso C, Abad A, Adánez J, de Diego LF, García-Labiano F. NiO/ $/ \mathrm{Al}_{2} \mathrm{O}_{3}$ oxygen carriers for chemical-looping combustion prepared by impregnation and deposition-precipitation methods. Fuel 2009; 88: 1016-1023.

[33] Jerndal E, Mattisson T, Thijs I, Snijkers F, Lyngfelt A. Investigation of $\mathrm{NiO} / \mathrm{NiAl}_{2} \mathrm{O}_{4}$ oxygen carriers for chemical-looping combustion produced by spraydrying. Int J Greenh Gas Con 2010; 4: 23-35.

[34] Mattisson T, Jerndal E, Linderholm C, Lyngfelt A. Reactivity of a spray-dried $\mathrm{NiO} / \mathrm{NiAl}_{2} \mathrm{O}_{4}$ oxygen carrier for chemical-looping combustion. Chem Eng Sci 2011; 66: 4636-4644.

[35] Rostrup-Nielsen JR, Sehested J, Norskov JK. Hydrogen and Synthesis Gas by Steam and $\mathrm{CO}_{2}$ Reforming. Adv Catal 2002; 47: 65-139.

[36] Rostrup-Nielsen JR, Rostrup-Nielsen T. Large-scale hydrogen production. Cat. Tech. 2002; 6: 150-159.

[37] Lyon R K., 1996. Method and apparatus for unmixed combustion as an alternative to fire; Patent Number 5, 509, 362.

[38] Noorman S, van Sint Annaland M, Kuipers H. Packed bed reactor technology for chemical-looping combustion. Ind Eng Chem Res 2007; 46: 4212-20. 
[39] Dahl IM, Bakken E, Larring Y, Spjelkavik AI, Hakonsen SF, Blom R. On the development of novel reactor concepts for chemical looping combustion. Energy Procedia 2009; 1: 1513-1519.

[40] KOPECS website http://www.kopecs.com/products/04_desuperheater_high_ temperature _valves. htm (Accessed on October 2013).

[41] Kumar RV, Lyon RK, Cole JA. Unmixed reforming: a novel authotermal cycling steam reforming process. In Advances in Hydrogen Energy; Gregoire Pedro, C. E., Laurent, F. W., Eds; Kluwer Academic Publishers: Higham, MA, USA, 2000, p 31.

[42] Abanades JC, Murillo R, Fernandez JR. Grasa G, Martinez I. New $\mathrm{CO}_{2}$ capture Process for Hydrogen production Combining $\mathrm{Ca}$ and $\mathrm{Cu}$ Chemical Loops. Env Sci Tech 2010; 44: 6901-6904.

[43] Noorman S, Gallucci F, van Sint Annaland M, Kuipers H. A theoretical investigation of CLC in packed beds. Part 2: Reactor model. Chem Eng J 2011; 167: 369-376.

[44] Hakonsen SF, Blom R. Chemical looping combustion in a rotating bed reactor Finding optimal process conditions for prototype reactor. Env Sci Tech 2011, 45: 96199626.

[45] Fernández JR, Abanades JC, Murillo R, Grasa G. Conceptual design of a hydrogen production process from natural gas with $\mathrm{CO} 2$ capture using a $\mathrm{Ca}-\mathrm{Cu}$ chemical loop. Int J Greenh Gas Con 2012; 6: 126-141.

[46] Spallina V, Gallucci F, Romano MC, Chiesa P, Lozza G, van Sint Annaland M. Investigation of heat management for CLC of syngas in packed bed reactors. Chem Eng J 2013; 225: 174-191.

[47] Fernández JR, Abanades JC, Murillo R. Modeling of $\mathrm{Cu}$ oxidation in adiabatic fixed-bed reactor with $\mathrm{N}_{2}$ recycling in a $\mathrm{Ca} / \mathrm{Cu}$ chemical loop. Chem Eng J 2013; 232: $442-452$.

[48] Fernández, JR, Abanades JC, Murillo R. Modeling of $\mathrm{Cu}$ oxidation in an adiabatic fixed-bed reactor with $\mathrm{N}_{2}$ recycling. Appl Energ 2014; 113: 1945-1951 
[49] Noorman S, Gallucci F, van Sint Annaland M, Kuipers H. Experimental investigation of a $\mathrm{CuO} / \mathrm{Al} 2 \mathrm{O} 3$ oxygen carrier for chemical-looping combustion. Ind Eng Chem Res 2010; 49: 9720-9728.

[50] Noorman S, Gallucci F, van Sint Annaland M, Kuipers H. A theoretical investigation of CLC in packed beds. Part 1: Particle model. Chem Eng J 2011; 167: 297-307.

[51] Noorman S, Gallucci F, van Sint Annaland M, Kuipers H. Experimental Investigation of Chemical-Looping Combustionin Packed Beds: A Parametric Study. Ind Eng Chem Res 2011; 50: 1968-1980.

[52] Hamers HP, Gallucci F, Cobden PD, Kimball E, van Sint Annaland M. A novel reactor configuration for packed bed chemical-looping combustion of syngas, Int $\mathrm{J}$ Greenh Gas Con 2013; 16: 1-12.

[53] Mattisson T, Järdnas A, Lyngfelt A. Reactivity of some metal oxides supported on alumina with alternating methane and oxygen-Application for chemical-looping combustion. Energ Fuel 2003; 17: 643-651.

[54] Consonni S, Lozza G, Pellicia G, Rossini S, Saviano F. Chemical-looping combustion for combined cycles with $\mathrm{CO}_{2}$ capture. J Eng Gas Turb Power 2006; 128: $525-534$.

[55] Bolland O, Mathieu P. Comparison of two $\mathrm{CO}_{2}$ removal options in combined cycle power plants. Energy Convers Mgmt 1998; 39: 1653-1663.

[56] Jonshagen, K, Sipocz N, Genrup M. A Novel Approach of Retrofitting a Combined Cycle With Post Combustion $\mathrm{CO}_{2}$ Capture. J Eng Gas Turb Power 2011; 133: 1-7.

[57] Johansson M, Mattisson T, Lyngfelt A. Creating a synergy effect by using mixed oxides of iron- and nickel oxides in the combustion of methane in a chemical-looping combustion reactor. Energ Fuel 2006; 20: 2399-2407.

[58] Hossain MM, de Lasa HI. Chemical-looping combustion (CLC) for inherent $\mathrm{CO}_{2}$ separations-a review. Chem Eng Sci 2008; 63: 4433-44 
[59] Mattison T, Lyngfelt A. Capture of $\mathrm{CO}_{2}$ using chemical-looping combustion. Proceedings of First Biennial Meeting of the Scandinavian-Nordic Section of the Combustion Institute, April 18-20, Goteborg, Sweden, 2001.

[60] van Selow ER, Cobden PD, van den Brink RW, Hufton JR, Wright A. Performance of sorption-enhanced water-gas shift as a pre-combustion $\mathrm{CO}_{2}$ capture technology. Energy Procedia 2009;1: 689-696.

[61] Wright AD, White V, Hufton JR, Quinn R, Codben PD, van Selow ER. CAESAR: Development of a SEWGS model for IGCC. Energy Procedia 2011; 4: 1147-1154.

[62] Martinez I, Murillo R, Grasa G, Fernandez JR, Abanades JC. Integrated Combined Cycle from Natural Gas with $\mathrm{CO}_{2}$ Capture Using a $\mathrm{Ca}-\mathrm{Cu}$ Chemical Loop. AIChE J. 2013; 59: 2780-2794.

[63] Martinez I, Murillo R, Grasa G, Fernandez JR, Abanades JC. Process design of a hydrogen production plant from natural gas with $\mathrm{CO}_{2}$ capture based on a novel $\mathrm{Ca} / \mathrm{Cu}$ chemical loop, Appl. Energ. 2014; 114: 192-208.

Table 1. Operating conditions and reactor characteristics corresponding to the reference case study.

\begin{tabular}{ll}
\hline Parameters & Values \\
\hline Inlet $\mathrm{CH}_{4}$ mass flow, $\mathrm{kg} / \mathrm{s}$ & 20 \\
Inlet gas temperature, ${ }^{\circ} \mathrm{C}$ & 150 \\
Pressure, bar & 20 \\
NiO content, wt. $\%$ & 60 \\
Particle size, $\mathrm{m}$ & 0.01 \\
Reactor length, $\mathrm{m}$ & 8 \\
Bed porosity & 0.5 \\
Bed bulk density, $\mathrm{kg} / \mathrm{m}^{3}$ & 1700 \\
\hline
\end{tabular}


Table 2. Temperature, pressure, flow rate and composition of the main gas streams in Figs. 2-4, for operating conditions in Table 1.

\begin{tabular}{|l|c|c|c|c|c|c|c|c|c|c|c|c|c|c|c|c|}
\hline GAS STREAMS & $\mathbf{1}$ & $\mathbf{2}$ & $\mathbf{4}$ & $\mathbf{5}$ & $\mathbf{6}$ & $\mathbf{7}$ & $\mathbf{8}$ & $\mathbf{1 0}$ & $\mathbf{1 1}$ & $\mathbf{1 2}$ & $\mathbf{1 3}$ & $\mathbf{1 6}$ & $\mathbf{1 7}$ & $\mathbf{1 8}$ & $\mathbf{1 9}$ & $\mathbf{2 0}$ \\
\hline Temperature ( $\left.{ }^{\circ} \mathbf{C}\right)$ & 150 & 150 & 150 & 150 & 150 & 150 & $570 / 150$ & $570 / 150$ & 150 & 150 & 1300 & 150 & 150 & 1300 & 150 & 150 \\
\hline Pressure (bar) & 20 & 20 & 19,3 & 19,3 & 20 & 20 & 19 & 19 & 20 & 20 & 19 & 20 & 20 & 19,35 & 18,7 & 18,7 \\
\hline $\begin{array}{l}\text { Molar flow } \\
(\mathbf{k m o l} / \mathbf{s})\end{array}$ & 1,25 & 7,14 & 3,75 & 5,89 & 3,96 & 15,32 & 14,5 & 11,36 & 6,28 & 24,28 & 22,96 & 1,66 & 6,41 & 6,06 & 1,31 & 4,75 \\
\hline \multicolumn{8}{|c|}{ Composition (\% v) } \\
\hline $\mathbf{H}_{\mathbf{2}} \mathbf{O}$ & - & 55 & 67 & 67 & - & - & - & - & - & - & - & - & - & - & - & - \\
\hline $\mathbf{O}_{2}$ & - & - & - & - & 21 & 5,4 & - & - & 21 & 5,4 & - & 21 & 5,4 & - & - & - \\
\hline $\mathbf{C O}_{2}$ & - & 28 & 33 & 33 & - & - & - & - & - & - & - & - & - & - & - & - \\
\hline $\mathbf{N}_{\mathbf{2}}$ & - & - & - & - & 79 & 94,6 & 100 & 100 & 79 & 94,6 & 100 & 79 & 94,6 & 100 & 100 & 100 \\
\hline $\mathbf{C H}_{\mathbf{4}}$ & 100 & 17 & - & - & - & - & - & - & - & - & - & - & - & - & - & - \\
\hline
\end{tabular}




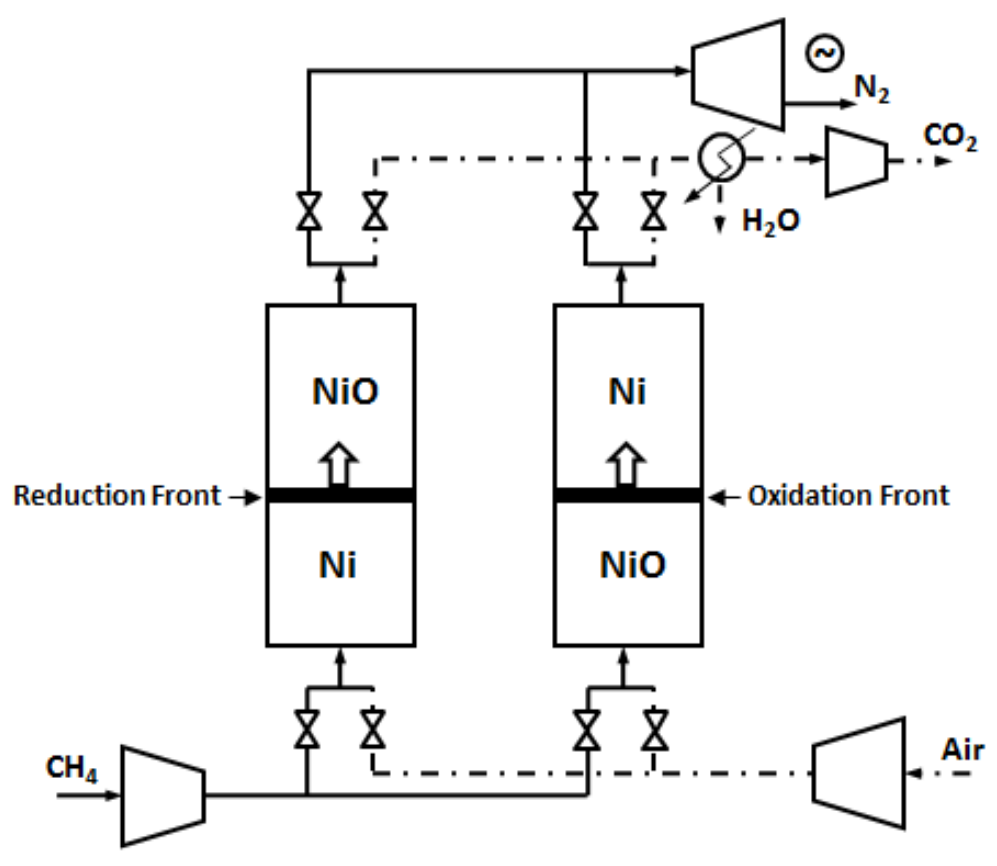

Fig. 1.

Basic scheme of a chemical looping combustion system with a Ni-based carrier in alternating fixed-bed reactors for power generation.
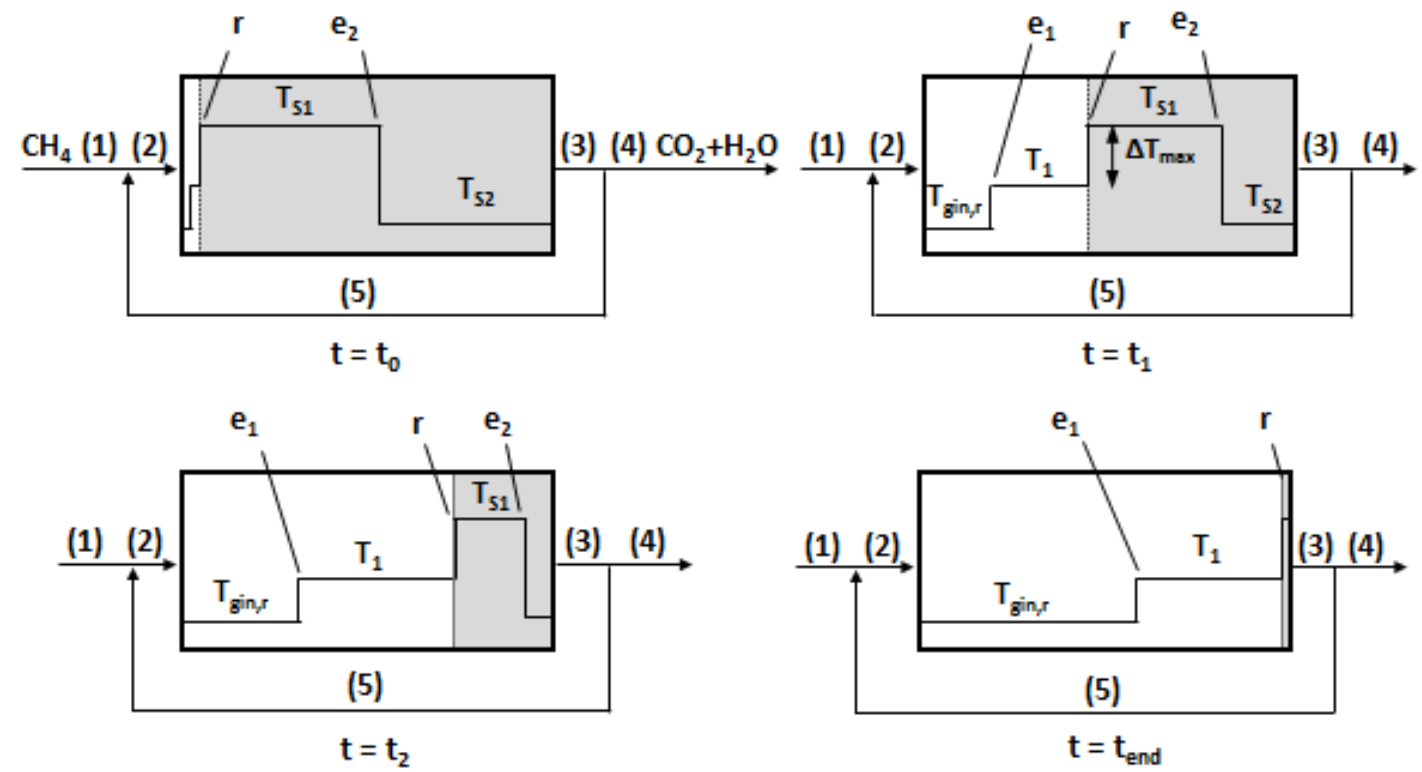

Fig. 2.

Evolution of the temperature profile during the reduction stage (A) of NiO-Ni with methane in a fixed-bed reactor $\left(r\right.$ : reaction front, $e_{i}$ : heat exchange front, white zone: reduced oxygen carrier, grey zone: oxidized oxygen carrier). 

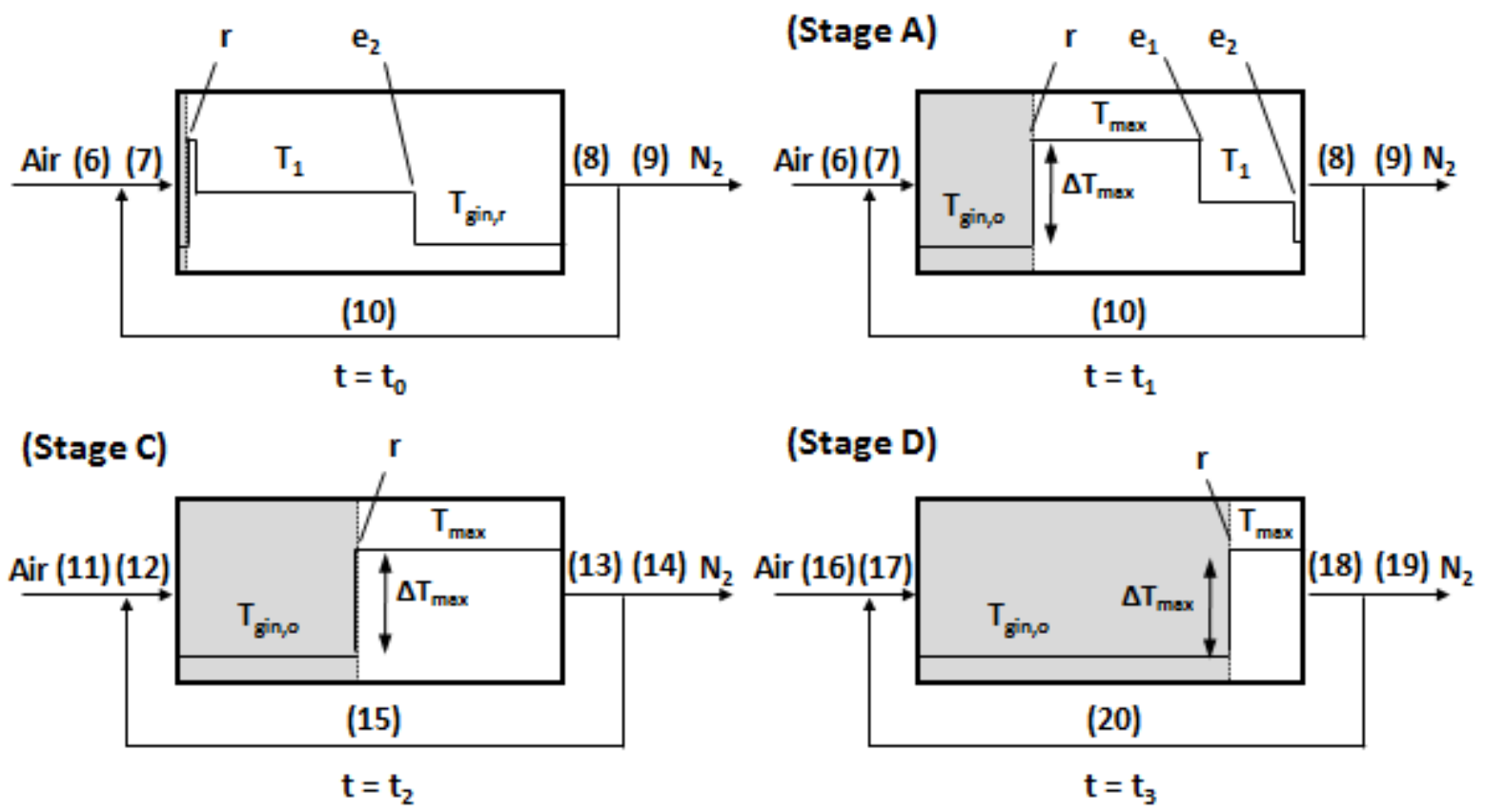

Fig. 3.

Evolution of the temperature profile during the oxidation stages of $\mathrm{Ni}-\mathrm{NiO}$ in a fixedbed reactor with $\mathrm{N}_{2}$ recycle ( $r$ : reaction front, $e_{i}$ : heat exchange front, white zone: reduced oxygen carrier, grey zone: oxidized oxygen carrier). Stage (B) is represented at the top, stage (C) at the bottom left and stage (D) at the bottom right.
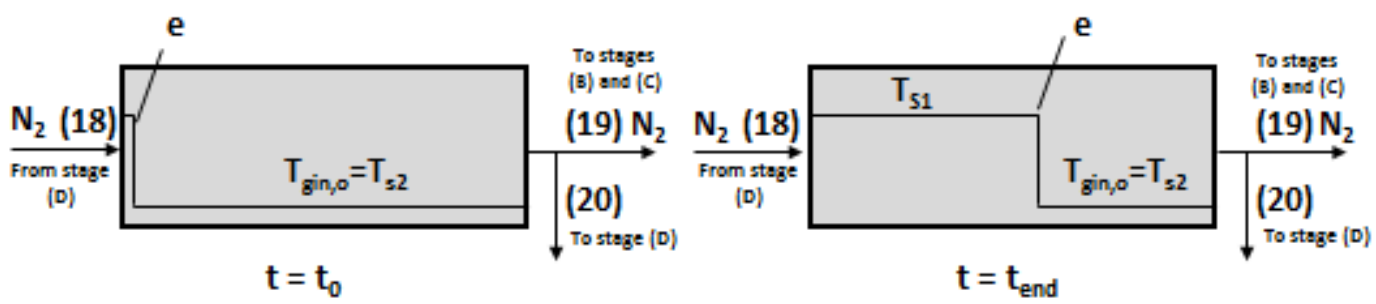

Fig. 4.

Evolution of the temperature profile during the additional heat exchange stage $(E)$ of the CLC process carried out in a fixed-bed reactor (e: heat exchange front, grey zone: oxidized oxygen carrier). 


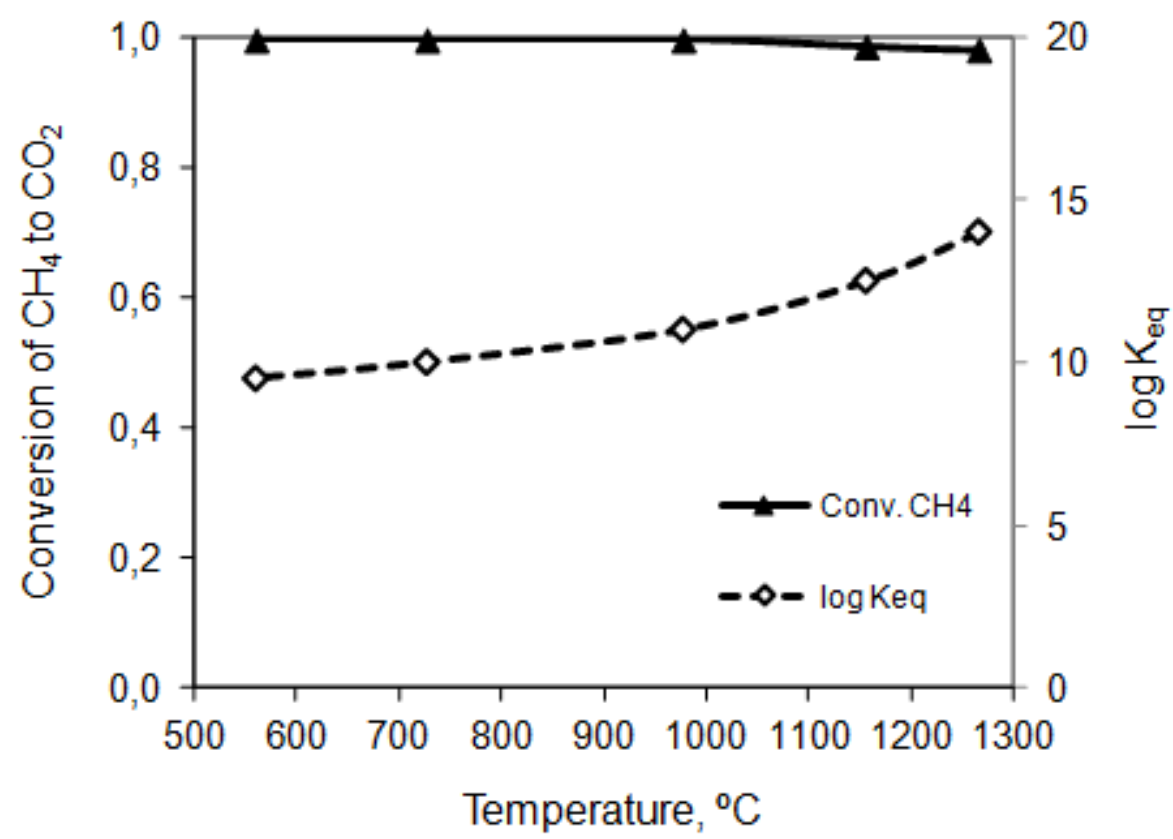

Fig. 5.

Effect of the temperature on the reduction of $\mathrm{NiO}-\mathrm{Ni}$ with $\mathrm{CH}_{4}$.

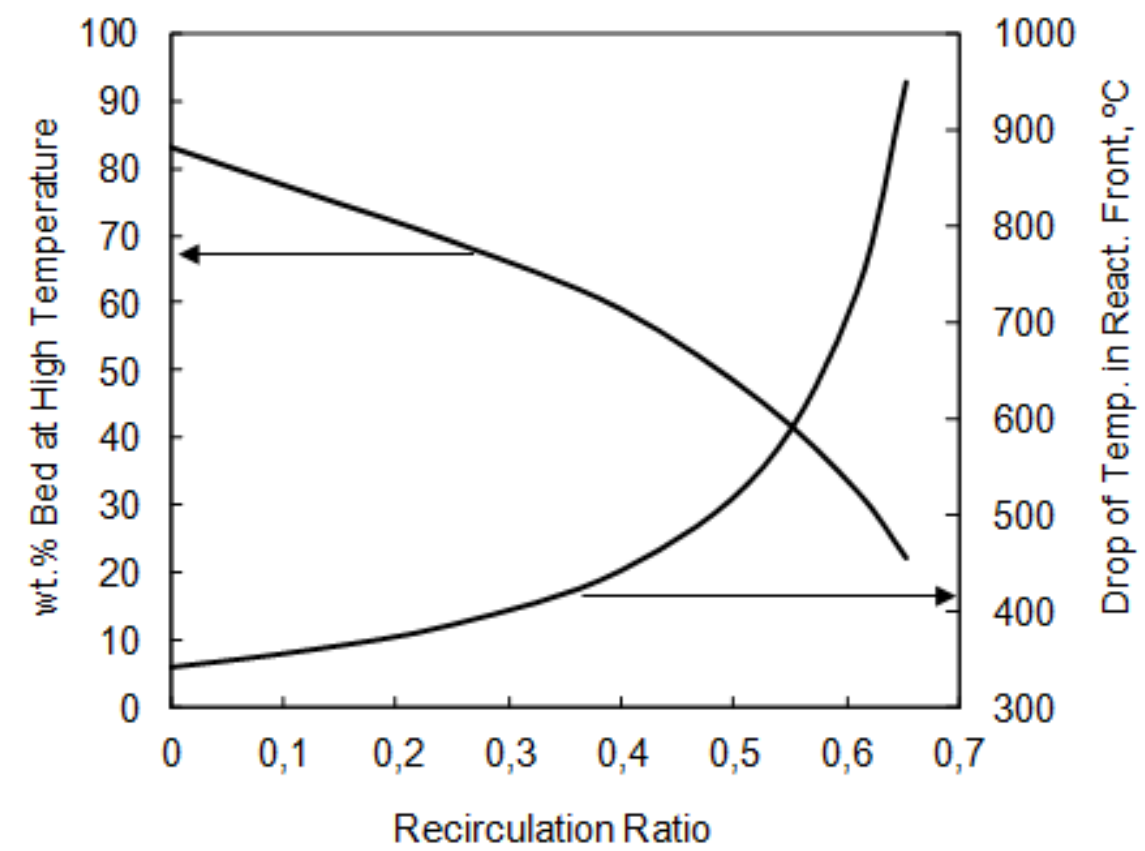

Fig. 6.

Effect of the recirculation ratio on the amount of solids at high temperature required for the reduction stage and on the drop in temperature in the reduction front (based on Eqs. (1), (2), (3), (4) and (5) with the input conditions shown in Table 1). 


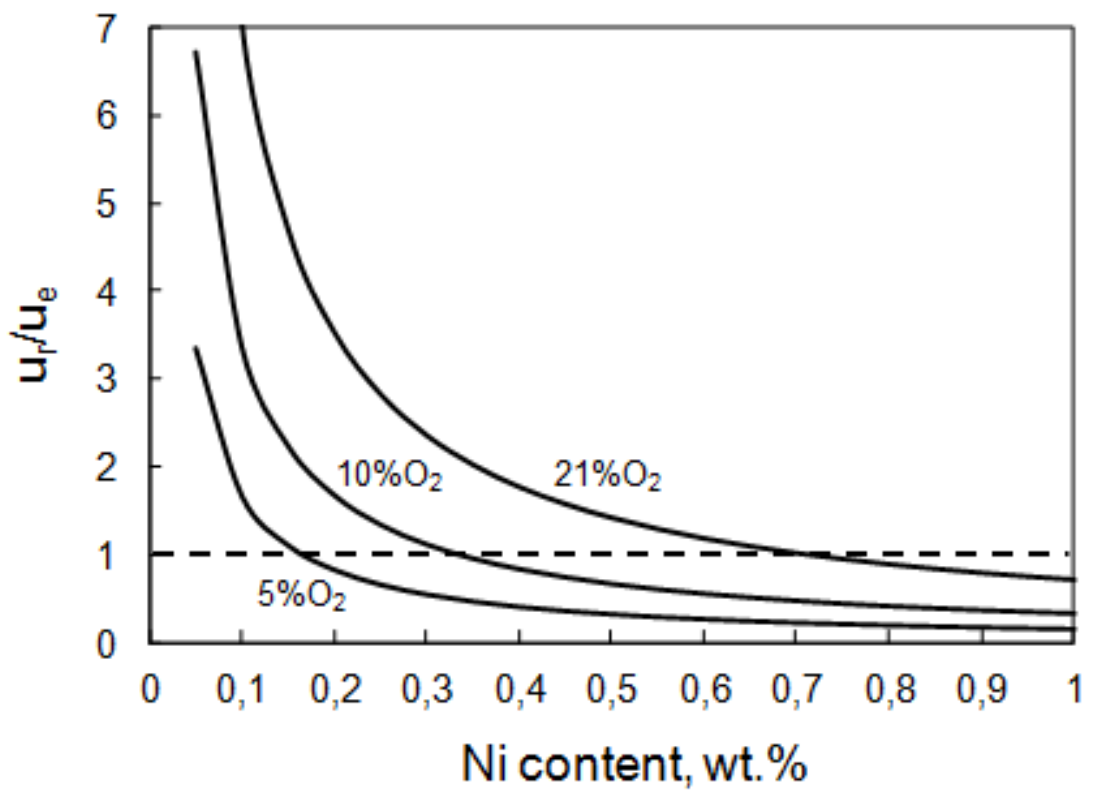

Fig. 7.

Reaction and heat exchange front velocity ratio as a function of the Ni content in the oxygen carrier and $\mathrm{O} 2$ content in the feed of the air reactor for the conditions of Table 1.

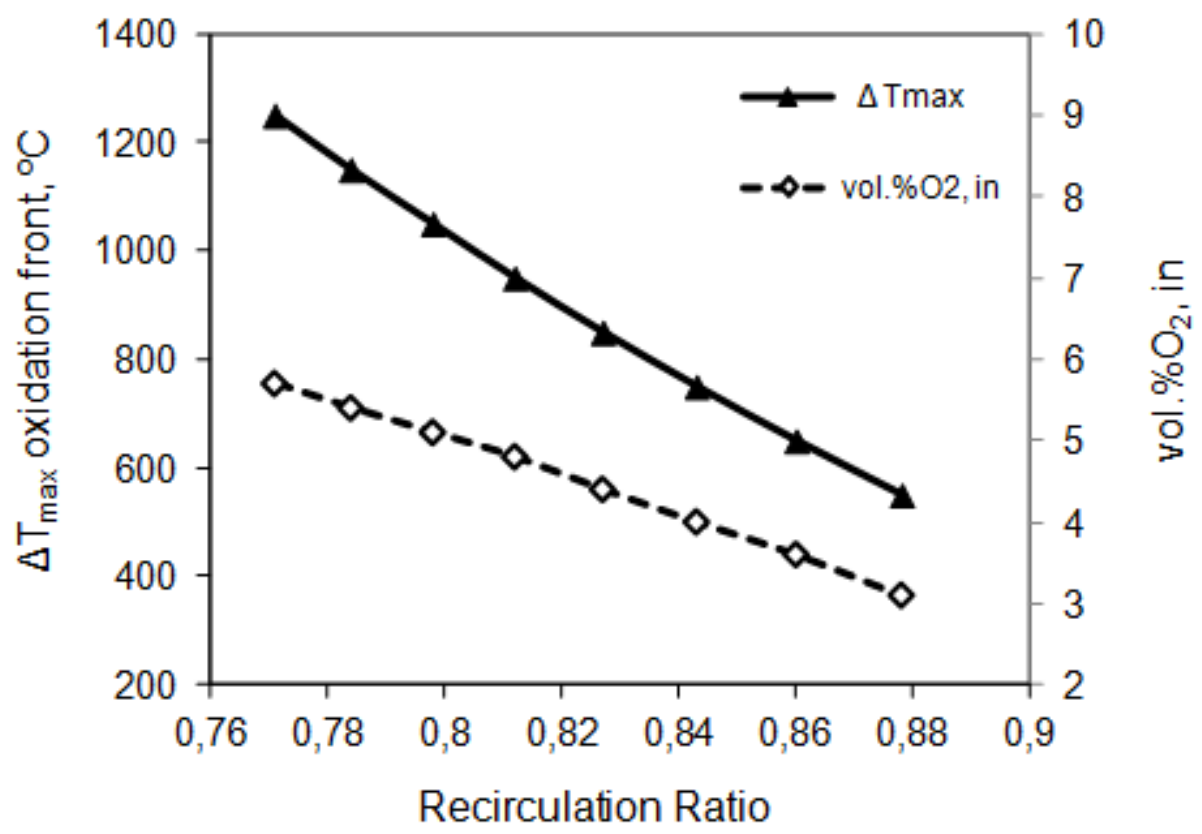

Fig. 8.

Influence of the recirculation ratio on the increase of temperature in the oxidation front and on the dilution of $\mathrm{O} 2$ in the feed (in the conditions shown in Table 1). 


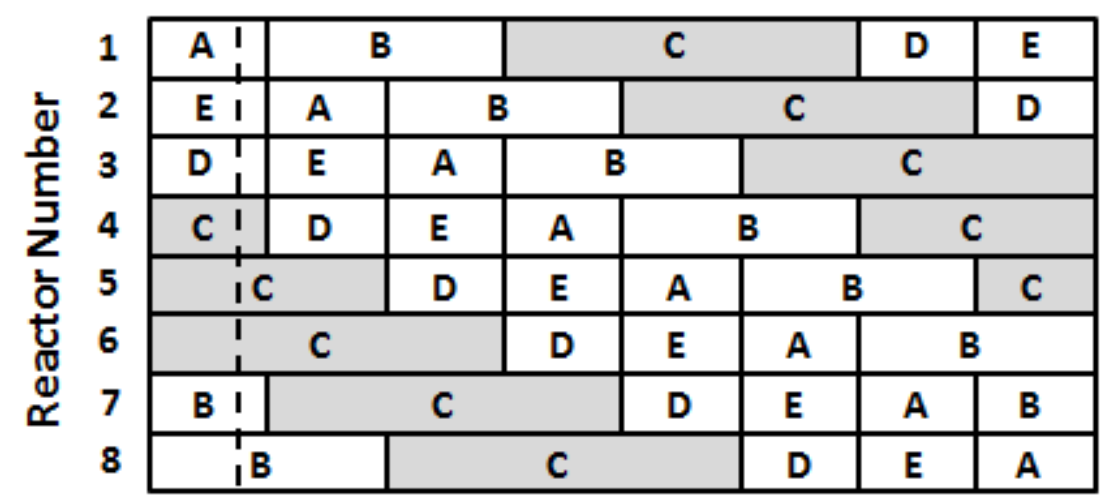

Fig. 9.

Operational diagram of the fixed-bed reactor configuration proposed for the chemical looping combustion of methane using a Ni-based carrier with nitrogen recycling (in the conditions shown in Table 1; the dotted line represents a snapshot of the process for a specific point in time detailed in Fig. 10). 


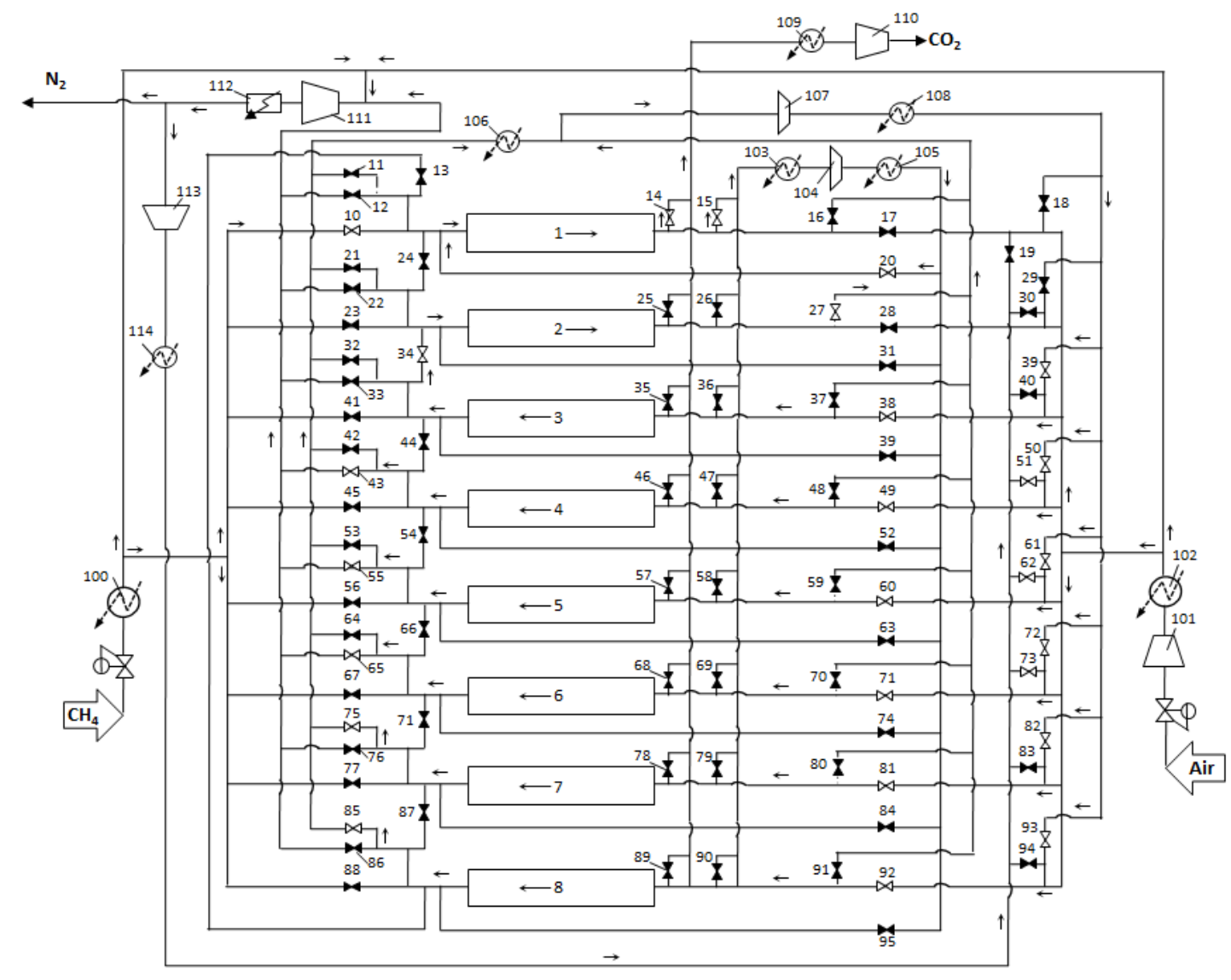

Fig. 10.

Process flow diagram of the proposed fixed-bed reactor configuration for the chemical looping combustion of methane at high pressure using a Ni-based carrier with nitrogen recycling (white valves are open and black valves are closed for the specific point in time marked by the dotted line detailed in Fig. 9). 